Reducing ICU Delirium by Promoting Early Mobility

\author{
Megan Ann Boehling \\ Roanoke, VA
}

Bachelors of Science in Nursing, University of Virginia, 2008

Masters of Science in Nursing, University of Virginia, 2016

A Scholarly Practice Project presented to the Graduate Faculty of the University of Virginia in Candidacy for the Degree of

Doctor of Nursing Practice

School of Nursing

University of Virginia

May 2017

Regina DeGennaro, DNP, CNS, RN, AOCN, CNL

Deborah Dillion, DNP, RN, ACNP-BC, CCRN, CHFN

Kyle Enfield, MD 


\begin{abstract}
Delirium is described as an acute confusional state characterized by fluctuating mental status, inattention, and either altered level of consciousness or disorganized thinking (Barr et al., 2013). In the intensive care unit (ICU), delirium has been shown to occur in $60 \%$ to $80 \%$ of mechanically ventilated patients and $40 \%$ to $60 \%$ of nonventilated patients. According to the most recent Pain, Agitation, and Delirium (PAD) Clinical Practice Guidelines from the American College of Critical Care Medicine (2013), early mobility is recommended to reduce delirium Project Purpose: The purpose of the project was to educate nurses about the implementation of an evidence based early mobility protocol to reduce the incidence of delirium in the adult ICU setting. The project also identified barriers to implementing early mobility protocols.

Method: A quality improvement project included a five-step approach; 1) assessed current nursing knowledge about early mobility and protocol implementation; 2) educated unit-based critical care nurses about the early mobility protocol; 3) provided nurses with an Early Mobility Worksheet for documentation of protocol implementation; 4) accessed the electronic medical record of those patients mobilized and trended delirium; 5) The delirium data was compared to the baseline group (pre-education) to identify if there was a reduction in delirium Results: Analysis was run excluding patients in the post-education group who were mobilized the day of or the day before ICU discharge. It was felt that the mobility intervention was not likely have an effect on delirium during the short time the patients remained in the ICU. After analysis, there was a statistically significant difference between the two groups (mean (SD) pre $44.1 \%(35.2 \%)$ versus post $20.5 \%(28.3 \%) ; \mathrm{p}=0.045)$.

Discussion: The findings indicate that the earlier patients are mobilized in the ICU the better the delirium outcomes.
\end{abstract}


Table of Contents

Background.................................................................. 4

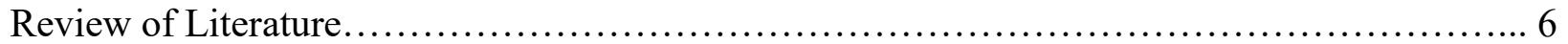

Methods

Purpose of the Study............................................................ 15

Hypothesis................................................................ 16

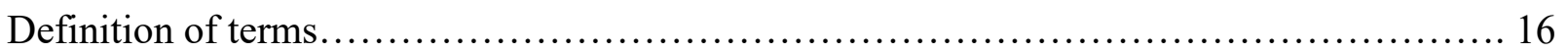

Research Design........................................................... 16

Sample.......................................................................... 16

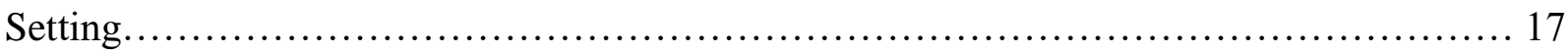

Nursing Knowledge and Education............................................ 17

Early Mobility Protocol ......................................................... 18

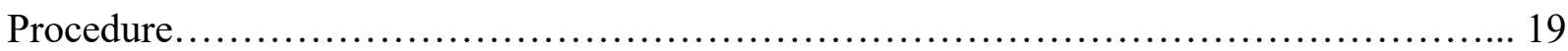

Measures............................................................... 19

Data Analysis.................................................................. 20

Protection of Human Subjects................................................ 21

Results

Nursing Education............................................................. 21

Delirium Outcomes.............................................................. 22

Barriers to Mobilization........................................................ 24

Discussion

Nursing Education............................................................. 24

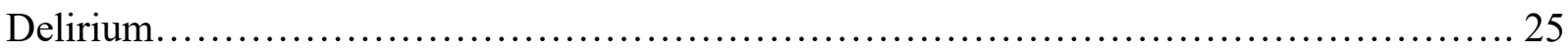

Barriers to Mobilization..................................................... 27

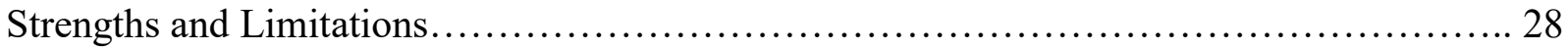

Nursing Practice Implications............................................. 28

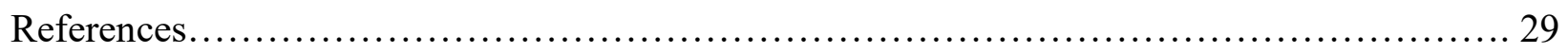

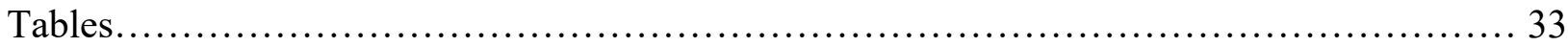

Appendices................................................................ 39 


\section{Reducing ICU Delirium by Promoting Early Mobility}

\section{Background}

Delirium is described in the Diagnostic and Statistical Manual of Mental DisordersFourth Edition (Text Revision) (DSM IV-TR) as an acute confusional state characterized by fluctuating mental status, inattention, and either altered level of consciousness or disorganized thinking. In the intensive care unit (ICU), delirium has been shown to occur in $60 \%$ to $80 \%$ of mechanically ventilated patients and $40 \%$ to $60 \%$ of nonventilated patients. Delirium can be subcategorized based on the patient's level of alertness into hyperactive, hypoactive, and mixed delirium. The hypoactive subtype is the most common accounting for $60 \%$ of delirium cases. Risk factors for delirium can be divided into three categories: 1) characteristics of acute illness, 2) patient or host factors, and 3) environmental or iatrogenic factors. While the risk factors for delirium are numerous, some of the more common causes include sedative, opiate, and benzodiazepine medications, age (greater than 65 years), sleep deprivation, immobilization, infection, and underlying dementia or previous delirium (Hipp \& Ely, 2012). The most commonly used tool for monitoring delirium in the ICU is the Confusion Assessment Method for the Intensive Care Unit (CAM-ICU). This tool has high sensitivity (93-100\%), high specificity (98-100\%), and high inter-rater reliability (kappa=0.96). The CAM-ICU is often used in combination with the Richmond Agitation-Sedation Score (RASS) or the Riker SedationAgitation Scale (SAS) (Hipp \& Ely, 2012). Delirium is important to identify and treat, because long term consequences including cognitive deficits and severe weakness lead to additional costs of $\$ 2500$ per patient or $\$ 6.9$ billion annually (O’Mahony, Murthy, Akunne \&Young, 2011).

According to the most recent clinical practice guidelines from the American College of Critical Care Medicine (2013), there are a few ways to prevent and treat delirium. Early mobility 
is recommended to reduce the incidence and duration of delirium. Pharmacologic prevention is not recommended because there is no compelling data to demonstrate that it reduces the incidence or duration of delirium (Barr et al., 2013). Delirium treatment and prevention is commonly included in a care bundle which are several interventions that together are shown to improve critically-ill patient's outcomes. One of the most common care bundles is the Awakening and Breathing Coordination, Delirium monitoring/management, and Early exercise/mobility (ABCDE bundle). This bundle is an example of an interprofessional evidencebased multicomponent ICU management strategy aimed at reducing sedation exposure, duration of mechanical ventilation, and ICU-acquired delirium and weakness (Balas et al., 2013). Based on this information, a literature review was performed to determine the effect of mobility protocols on the incidence and duration of delirium.

In the development of this study, Avedis Donabedian's conceptual framework for assessing quality of care was utilized. Donabedian (1988) acknowledges that there are many methods for evaluating quality of care, but highlights three specific categories: structure, process, and outcome. To properly assess quality these three categories must have an established relationship. Donabedian (1988) states, "this three-part approach to quality assessment is possible only because good structure increases the likelihood of good process, and good process increases the likelihood of good outcome (p. 1745)." Structure can be described as the setting in which care occurs. This includes material resources (facilities, equipment, and money), human resources (number and qualifications of staff), and organization structure (methods of reimbursement and staff organization). Process describes the care given and received including both patient and staff activities. Lastly, outcome is the effect of care on patients' health status (Donabedian, 1988). All aspects of the structure, process, and outcome framework are addressed 
in this study. The structure of this project includes the MICU, mobility equipment, and the qualified staff needed to aid in mobilizing patients. The process is the implementation of the early mobility protocol. The outcome evaluated will be the delirium data.

\section{Literature Review}

A literature review was performed to determine if early mobility protocols reduce the incidence or duration of delirium in adult ICU patients. Key terms searched were: "delirium," “intensive care unit" or "ICU," "early mobility" or "early ambulation" or "physical therapy" or "rehabilitation." The inclusion criteria for articles were qualitative or quantitative studies of delirium outcomes, studies with implementation of a mobility protocol, reports secondary data including ICU and hospital length of stay (LOS) and ventilator-free days. Exclusion criteria were articles before 2000, published in language other than English, studies that do not report delirium outcome data, and studies that do not implement a mobility protocol. The above key terms were used to conduct database searches in OVID, Cochrane, and CINAHL, resulting in 33, 7 and 66 articles respectively. Based on a review of abstracts regarding inclusion criteria, 15 articles were retained from the OVID search and one article was retained from the Cochrane search. After duplicate articles were excluded the CINAHL search 16 remained and 5 were retained. After completing an ancestry search, 6 additional articles were included. Based on inclusion and exclusion criteria and further analysis of articles, 19 of the 27 articles were excluded from the review of literature. Of the articles excluded, five did not implement a mobility protocol, seven did not report delirium outcomes, four reported data from the same studies, and three were a duplication of guideline recommendations. For the review of literature, eight articles were retained.

\section{Results}


The review of literature was conducted to determine whether early mobility reduced the incidence or duration of delirium and included two literature reviews and six studies. Of the studies included, one was a randomized control trial and five were prospective cohort studies. A summary of the studies is provided in Table 1.

Published literature reviews. Barr et al.'s (2013) literature review was conducted to review, evaluate, and summarize the literature and to develop clinical statements and recommendations for pain, agitation and sedation, and delirium management in the adult ICU patient. The literature review was conducted by a 20-person multidisciplinary, multiinstitutional task force who reviewed over 19,000 studies through 2010. The quality of evidence for each recommendation and statement were ranked as high (A), moderate (B), or low/very low (C). Level A evidence included that delirium is associated with increased cost and increased ICU and hospital LOS in adult ICU patients. The Confusion Assessment Method for the ICU (CAM-ICU) and the Intensive Care Delirium Screening Checklist (ICDSC) are the most valid and reliable delirium monitoring tools in adult ICU patients (Barr et al., 2013). Level B evidence included early mobilization of adult ICU patients reduces the incidence and duration of delirium. Also, delirium is associated with post-ICU cognitive impairment. This review of literature indicates that early mobility is effective at reducing the incidence and duration of delirium (Barr et al., 2013).

Collinsworth, Priest, Campbell, Vasilevskis \& Masica (2016) completed a literature review to examine the effectiveness, implementation, and costs of multifaceted care approaches for the prevention and mitigation of delirium in patients hospitalized in the ICU. The search was limited to English studies from January 1, 1988 to March 31, 2014. Randomized control trials and comparative studies of multifaceted care approaches with delirium in ICU patients as an 
outcome were included. A total of 14 studies met the inclusion criteria. Of those studies, eight examine outcome measures pertaining to delirium. The interventions in these studies had a combination of various therapies including daily breathing trials, reorientation, early rehabilitation, pain assessment, and delirium screening. Of the eight studies, five found that multifaceted care approaches were associated with significant reductions in incidence of delirium, duration of delirium, or days patients spent awake and not delirious. Five studies examined mechanical ventilation and four found that multifaceted care approaches were associated with significant reductions in ventilator days. Additionally, three studies found that the multicomponent care approaches were associated with significant decreases in both ICU and/or hospital LOS. This review of literature illustrates that early mobility in addition to other interventions are effective in reducing the incidence and duration of delirium.

Early mobility studies with delirium outcome measures. Balas, Burke, Gannon, et al. (2014) performed a prospective cohort study to evaluate the effectiveness and safety of implementing the Awakening and Breathing Coordination, Delirium monitoring/management, and Early exercise/mobility (ABCDE) bundle into everyday practice. Previous studies of the ABCDE bundle focused on mechanically ventilated patients, but Balas et al. wanted to evaluate the ABCDE bundle implementation for all ICU patients regardless of mechanical ventilation. The study was implemented in five adult ICUs, one step-down unit and one oncology and hematology special care unit located in a 624-bed tertiary medical center. A total of 296 patients were enrolled in the study. Of those enrolled, 146 were the pre-bundle control patients and 150 were the post-bundle implementation study group. The ABCDE bundle included daily spontaneous awakening trials and daily spontaneous breathing trials if the patient received a continuous infusion of sedative medication and/or mechanical ventilation within the past 24 
hours. Additionally, the bundle required delirium documentation using the Richmond AgitationSedation Scale (RASS) every two hours and Confusion Assessment Method for the ICU (CAMICU) every eight hours. Lastly, mobility was assessed based on physical therapy consultation and daily mobilization out of bed. Outcomes measures evaluated the effectiveness of the ABCDE bundle and included ventilator-free days during a 28-day period, prevalence of delirium, duration of delirium, percent of ICU days with delirium, mobilized out of bed during ICU stay, and time to discharge from the ICU and hospital. Statistical analysis was performed comparing the two groups and comparing outcome measures based on pre-bundle and post-bundle implementation data. Of the mechanically ventilated patients, the post-bundle implementation group had more ventilator free days than those in the pre-bundle implementation group. The prebundle median was 21 days (range 0-25 days) and the post-bundle median was 24 days (range 726 days); $\mathrm{p}=0.04$. Patients treated with the $\mathrm{ABCDE}$ bundle experienced less delirium (prebundle $62.3 \%$ versus post-bundle $48.7 \%$; $=0.02$ ). Additionally, patients treated with the ABCDE bundle had a lower percentage of delirious ICU days (pre-bundle 50\% versus postbundle 33.3\%; $\mathrm{p}=0.003$ ) (Balas et al., 2014). Delirium duration was not significantly different between groups. The post-bundle group had a higher percentage of mobilized patients (prebundle $48 \%$ versus post-bundle $66 \%, \mathrm{p}=0.002$ ). There was no statistically significant difference in ICU or hospital discharge between the two groups. Overall, implementation of the ABCDE bundle increased ventilator-free days, reduced delirium, and increased the likelihood of patients being mobilized (Balas et al., 2014).

Foster and Kelly (2013) conducted a prospective, cohort pilot study to determine the feasibility of and to test a multicomponent, nonpharmacological, nurse-driven intervention to prevent delirium. The pilot study took place in a MICU in a Magnet-designated community 
hospital in a major metropolitan city in Southwest United States. Inclusion criteria for the study were patients 18 years or older, hemodynamically stable, and hearing able. After informed consent, 32 patients enrolled in the study. The multicomponent intervention included daily sedation cessation, promotion of sleep-wake cycles, promotion of meaningful sensory stimulation, patient mobility, and preferred music listening. After a training period, the intervention was initiated and post-intervention data collection began after the first week of implementation and continued for two months. This data was compared to baseline delirium data that was collected over one month on all MICU patients. The CAM-ICU tool was used to collect delirium data. The baseline data included 216 patient delirium assessments. Data was missing for $24.07 \%$ of the assessments. Of the remaining assessments, $28 \%$ were positive for delirium, $12 \%$ were unable to be assessed, and $60 \%$ were negative for delirium. In the postintervention phase 92 patient delirium assessments were reviewed. Data was missing for $8.69 \%$ of delirium assessments. Of those remaining, $31 \%$ were positive for delirium, $1 \%$ was unable to be assessed, and $68 \%$ were negative (Foster \& Kelly, 2013). Overall, adherence to the intervention was low with barriers identified including documentation deficiencies, patient/family consent process, and lack of support from other disciplines, mobility protocol adherence, and poor sleep promotion (Foster \& Kelly, 2013).

Fraser, Spiva, Forman \& Hallen (2015), conducted a prospective cohort study to assess the effect of receiving physical therapy from a dedicated mobility team on patient quality-of-care outcomes, sedation and delirium measures, and functional outcomes. The study was implemented in three ICUs at a community acute care hospital in Southeastern United States. A total of 132 patients were included in the study; 66 patients received routine care and 66 received the early mobility intervention. The early mobility intervention was carried out by a dedicated 
ICU mobility team including a physical therapist, a critical care nurse and a mobility technician. Each day the mobility team visited patients they have previously seen as well as new consults. The intervention consisted of four progressive mobility phases and which phase the patient received was based on patient ability. The intervention period was 3 months and outcomes measures included hospital LOS, ICU LOS, duration of mechanical ventilation, and days with no delirium. Outcome measures were compared between the routine care group and the intervention group. The mean hospital LOS was not significantly different between the two groups (routine care 10.7 days versus mobility 12.6 days, $\mathrm{p}=0.111$ ). Additionally, there was no difference in the mean ICU LOS (routine care 6.5 days versus 6.4 days, $p=0.973$ ). The mean duration of mechanical ventilation was not significantly different between groups (routine care 3.3 days versus 3.8 days, $\mathrm{p}=0.52$ ) (Fraser, Spiva, Forman \& Hallen, 2015). Lastly, the mobility protocol did increase the mean days without delirium (routine care 3.6 days versus mobility 5.05 days, $\mathrm{p}=0.05$ ). Overall, the mobility protocol demonstrated no effect on outcomes in the majority of measures analyzed, except for a reduction in the number of days that patients exhibited delirium (Fraser, Spiva, Forman \& Hallen, 2015).

Inouye et al. (2003) implemented a prospective cohort study to examine the impact of adherence to effective nonpharmacologic interventions on delirium prevention. The study was carried out on a general medicine floor at Yale New Haven Hospital from March 1995-March 1998. Patient inclusion criteria for the study were 70 years or older, no delirium at admission, and at least intermediate risk of delirium based on risk factors. The final study sample included 422 patients. The intervention protocols implemented for all patients included orientation, therapeutic activities, and mobility. The mobility protocol was to provide ambulation or active range-of-motion activities three times daily. The primary outcome measured was new-onset 
delirium during hospitalization, defined according to the CAM criteria. Delirium rates were analyzed based on adherence to the various protocols. Adherence to the protocols was measured daily. Adherence groups were divided into low, intermediate, and high. For the mobility protocol, low adherence was $0 \%$ to $49 \%$, intermediate was $50 \%$ to $74 \%$ and high was $75 \%$ to $100 \%$. The rate of delirium for each adherence group was reported. For the low adherence group the delirium rate was 14\%, intermediate 10\% and high 3\% (Inouye et al., 2003). The difference between the groups was statistically significant with $\mathrm{p}=0.01$. Overall, higher adherence to the protocols led to lower rates of delirium (Inouye et al., 2003.

Needham et al. (2010) conducted a prospective cohort quality improvement (QI) project to increase rehabilitation-related consults and treatments in order to improve functional mobility, to improve patient sedation and delirium status, and evaluate the effects on length of stay. The QI project was implemented in Johns Hopkins Hospital's Medical ICU (MICU). The study involved a 3-month pre-QI project control period followed by a 4-month QI project implementation period. The pre-QI project group had 27 patients and the QI project group had 30 patients all of whom had been intubated for four or more days in the MICU. Before implementation of the QI project, the staff underwent education about early mobility in the ICU. Additionally, standard work and checklists were used to remind staff about rehabilitation consults and early mobilization in. The staff also held weekly interdisciplinary meetings about the progress and barriers of the QI project. After QI project implementation, the proportion of physical therapy consultations increased (pre-QI period 59\% versus QI period 93\%; $\mathrm{p}=0.004$ ). The proportion of non-delirious ICU days was higher in the QI period group (pre-QI period 21\% versus QI period 53\%; p=0.003) (Needham et al., 2010). Functional mobility as measured by the proportion of mobility treatments with sitting at the edge of bed or greater was also higher in the 
QI period group (pre-QI period 56\% versus QI period 78\%; $\mathrm{p}=0.03$ ). Lastly, MICU and hospital LOS were significantly reduced in the QI period group. The average MICU LOS for the QI period group was decreased (pre-implementation group 7.0 days versus QI period group 4.9 days, $\mathrm{p}=0.02$ ). The average hospital LOS for the pre-QI group was 17.2 days and 14.1 days in the QI period group with $\mathrm{p}=0.03$. After implementation of the QI project, patients experienced increased physical therapy consultations and functional mobility which resulted in an improvement in non-delirious ICU days and a reduction in MICU and hospital LOS (Needham et al., 2010).

Schweickert et al. (2009) conducted a randomized controlled trial to evaluate the efficacy of a physical and occupational therapy on functional outcomes for patients receiving mechanical ventilation in the ICU. The study was implemented in the medical ICUs at the University of Chicago Medical Center and the University of Iowa Hospitals. The participants were all adults (18 years or older) who had been on mechanical ventilation for less than 72 hours and will continue on the ventilator for at least 24 hours. The study included 104 patients; 55 in the control group and 49 in the intervention group. The intervention included physical and occupation therapy in coordination with an interruption in sedation. The level of mobility was dependent on patient ability. Outcomes measured included days with ICU delirium, percent of time in ICU with delirium, ventilator-free days (out of 28 days), duration of mechanical ventilation, ICU LOS, and hospital LOS. Patients who received the therapy protocol experienced fewer delirium days and less time in the ICU with delirium (intervention 2.0 days versus control 4.0 days, $\mathrm{p}=0.03$ and intervention $33 \%$ versus control $57 \%, \mathrm{p}=0.02)$. The intervention group also experienced more ventilator free days (intervention 23.5 versus control 21.1, $\mathrm{p}=0.05$ ) (Schweickert et al., 2009). Additionally, the duration of mechanical ventilation 
was reduced for the intervention group (intervention 3.4 days versus control 6.1 days, $\mathrm{p}=0.02$ ).

The ICU and hospital LOS was not significantly different between the two groups (intervention 5.9 versus control 7.9, $\mathrm{p}=0.08$ and intervention 13.5 versus control $12.9, \mathrm{p}=0.93$ ). Overall, the physical and occupational therapy reduced delirium and mechanical ventilation, but had no effect on length of stay (Schweickert et al., 2009).

\section{Discussion}

This review of literature was conducted to evaluate the effectiveness of mobility interventions to reduce the incidence and duration of delirium. The review included two reviews of literature, one randomized control trial, and five prospective cohort studies. Barr et al., (2013) found moderate strength evidence to support the hypothesis that early mobility protocols reduce the incidence and duration of delirium. Collinsworth et al., (2016) found that multifaceted care approaches that included mobility were associated with significant reductions in the incidence of delirium, duration of delirium, or days patients spent awake and not delirious. Schweickert et al., (2009) demonstrated in a randomized control trial that implementing physical and occupational therapy for intubated ICU patients reduced the duration of delirium. Lastly, five of the six prospective cohort studies reported that early mobility decreased the incidence and/or the duration of delirium. Overall, the review of literature reveals that mobility is an effective intervention for reducing the incidence and duration of delirium. However, more studies are needed to further evaluate the efficacy of the intervention because of the relatively small number of studies published. 
When compared to no nursing education, does implementing nursing education about an evidence based early mobility protocol reduce incidence of delirium for patients in adult intensive care units (ICU)?

\section{Methods}

According to the American College of Critical Care Medicine (2013), early mobility is the primary nonpharmacological recommendation for reducing the incidence and duration of delirium. Based on the literature review, an educational project was conducted MICU (setting) to determine the effectiveness of an early mobility protocol on reducing the incidence of delirium. The project included a five-step approach; 1) assessed current nursing knowledge about early mobility and protocol implementation in the critical care unit; 2) educated unit-based critical care nurses about the early mobility protocol and its significance in patient care; 3) provided nurses with an Early Mobility Worksheet for documentation of protocol implementation; 4) accessed the electronic medical record of those patients mobilized and trended delirium data while patient remained in the ICU; 5) the delirium data was compared to the pre-education group (pre group) to identify if there was a reduction in delirium incidence. This study will contribute to the developing body of evidence regarding early mobility and delirium prevention.

\section{Purpose of the study}

The purpose of the project was to educate nurses about the implementation of an evidence based early mobility protocol to reduce the incidence of delirium in the adult ICU setting. The project also identified barriers to implementing early mobility protocols. This project was designed to increase nursing knowledge regarding early mobility, encourage mobilization in intensive care patients, to decrease the incidence of delirium, and to identify barriers to early mobilization in the intensive care setting. 


\section{Hypothesis}

Educating nurses about the implementation of an evidence based early mobility protocol will reduce the incidence of delirium in an adult MICU.

\section{Definition of terms}

The key terms for this project are as follows:

Delirium: An acute confusional state characterized by fluctuating mental status, inattention, and either altered level of consciousness or disorganized thinking (Hipp \& Ely, 2012)

Early mobility: Assessing a patient's readiness and ability to be mobilized within 24 hours of admission to the ICU (Early Mobility Toolkit, 2014).

\section{Research Design}

This study was a quality improvement project with a retrospective pre-post cohort design.

\section{Sample}

Data for the study was obtained through patient charts via the electronic medical record (EMR). The sample was MICU patients deemed eligible by the protocol to receive early mobility. The sample data was gathered over a one month time period to achieve a sample size of $30(n=30)$. Inclusion criteria included: adult MICU patients (over 18 years of age) and patient admitted to the MICU for more than 24 hours. Exclusion criteria included: inability to follow commands, RASS score of -3 or less, mechanical ventilation with positive end-expiratory pressure (PEEP) greater than 10, oxygen supplementation with greater than $70 \%$ fraction of inspired oxygen $(\mathrm{FiO} 2)$, respiratory rate less than 5 or greater than 40 breaths per minute, heart rate less than 50 or greater than 140 beats per minute, mean arterial pressure (MAP) less than 55 or greater than 140, systolic blood pressure (SBP) less than 90 or greater than 200 , new or increasing vasopressor infusions or new cardiac arrhythmia. 


\section{Setting}

The setting for the study was the MICU of a large academic medical center in the Southeast United States. The MICU is a 28 bed unit within the roughly 600 bed medical center. The MICU treats a wide array of critically ill patients with diagnoses that include septic shock, liver failure, kidney disease, gastrointestinal bleeding, hypertensive emergency, chronic lung diseases, cancer, alcohol/drug withdraw, pneumonia, acute respiratory distress syndrome, severe allergic reactions and others. Approval for study implementation in the MICU was granted by the medical director and nurse manager of the unit. The Human Subjects Research IRB approved the study protocol (Appendix A).

\section{Nursing Knowledge and Education}

Nursing knowledge about the evidence based early mobility protocol and its significance in patient care was assessed using an anonymous survey prior to nursing education. The survey was sent out via e-mail, returned via email on the secure server, and the results were stored in Excel. The education of the critical care nurses was multi-faceted. First, information regarding the evidence based early mobility protocol and its importance in patient care was sent out to all medical intensive care nurses via email. The email also had supporting evidence from the most recent Pain, Agitation, and Delirium (PAD) Clinical Practice Guidelines from the American College of Critical Care Medicine (2013). Information regarding project implementation and the Early Mobility Worksheet was also sent out to familiarize the nurses with the format. The same information was presented at the MICU staff meeting which occurs the first Tuesday of every month. Lastly, one-on-one education was provided on the unit the week before project implementation. One-on-one education was provided to all nurses during day shift for seven consecutive days. While education was occurring, the unit staffed 95 nurses. Of those nurses, 
65 received one-on-one education. The 30 nurses who did not receive one-on-one education were working night shift and the project was designed to be implemented during day shift. The researcher was also available throughout project implementation to respond to the staff's questions.

\section{The Early Mobility Protocol}

The early mobility protocol was adapted from Johns Hopkins Armstrong Institute for Patient Safety and Quality's Early Mobility Toolkit (Early Mobility Toolkit, 2014) (Appendix B). The early mobility protocol consisted of a patient assessment and progressive levels of mobility. If the patient passed the assessment (stated in inclusion and exclusion criteria above), then progressive mobility was started based on patient ability. The progressive mobility consisted of four levels. The first level consisted of turning the patient in bed every two hours and passive range of motion. Level two included passive transfer to chair or chair position in bed. Level three included standing with assistance or sitting out of bed. Level four consisted of active transfer to chair, standing with minimum or no assistance, and ambulating.

The early mobility protocol first required identification of the patients who were eligible for mobilization. The initial activity screening was performed for all patients within 24 hours of admission to the ICU. This initial screening was performed during interdisciplinary rounds. After orders were placed for the mobility protocol, the bedside nurse performed a basic assessment to determine if mobilizing the patient was safe and appropriate. The basic assessment determined neurologic, respiratory, and cardiovascular stability. The patient failed the basic assessment if any of the exclusion criteria (above) were met. If the patient failed the assessment, the patient only received mobility level one until stabilized. The patients who passed the basic assessment were mobilized starting at level two and progressed based on patient 
ability. After the patient was mobilized, the nurse documented the mobility level reached on the Mobility Protocol Worksheet (described below).

\section{Procedure}

After determining which patients were mobilized, the patient medical records were accessed via the EMR by the researcher. The data were obtained manually from the EMR for each patient. For each patient mobilized, the CAM-ICU score was obtained starting with the first day mobilized until the patient was discharged from the ICU. The data were collected from the Mobility Protocol Worksheet and the EMR. The Mobility Protocol Worksheets were collected daily and stored in a locked office. After collection, data were de-identified and organized using Excel. The worksheets were disposed of in appropriate shred bins.

The mobility data was compared to a pre-education group obtained before nursing education regarding mobility protocol implementation. The pre-education data were collected on thirty random patients starting on September 1, 2016. The data were obtained by information technology experts from the medical center. The data were de-identified and stored in Excel.

\section{Measures}

Demographic data were obtained from the EMR and included age, gender, ICU LOS, and hospital LOS. Delirium data were obtained for those patients who were mobilized using the Mobility Protocol Worksheet (Appendix C). The worksheet was a quality improvement data collection instrument that was paired with EMR delirium data. The worksheet had several components and developed in collaboration with a MICU clinical nurse specialist. First, there were places for the date and a patient information label. Next, the early mobility protocol was on the worksheet as a reminder for the nurses. Below the mobility protocol illustration, there were two questions. First, was the patient mobilized to a level greater than level one? The next 
question: If not, why? The worksheet had options to choose between to respond to the question including: patient failed basic assessment, patient/family refused, time, staffing, lack of equipment, safety, other (comment). The nurse was asked to circle one of the options. An example of the Mobility Protocol Worksheet is in an appendix below (Appendix C). Delirium was measured using the CAM-ICU tool. This measure has high sensitivity (93-100\%), high specificity (98-100\%), and high inter-rater reliability (kappa=0.96) (Ely et al., 2001).

\section{Data Analysis}

The data were analyzed using the statistical package SPSS version 24. Demographic data were analyzed using descriptive statistics such as means, percentages, and frequencies. Due to the skewness of the ICU and hospital LOS data, medians and interquartile range (IQR) were used to describe the data. To test for a statistically significant difference between the pre and posteducation groups' length of stays, a Mann-Whitney U test was performed. Statistical analysis for the delirium data was run in two ways. First, the average number of delirium positive days was calculated for each patient in the pre and post group. Due to skewness of the pre and post delirium data, a Mann-Whitney U test was performed to analyze for a statistically significant difference between the two groups. Additionally, before any analysis was performed, it was noted that many patients in the post-education group were mobilized on the day of or the day before discharge. It was believe that the mobility intervention was not likely to have an effect on delirium for these patients due to the short period of time the patient remained in the ICU. Therefore, an additional analysis was performed excluding the patients who were mobilized the day of or the day before ICU discharge. The patients in the pre group with only one or two day ICU stays were also excluded. An independent-t test was run comparing the two groups to test for statistical significance. (Norman \& Streiner, 2003). 


\section{Protection of Human Subjects}

The appropriate IRB application was submitted and approved. The risk of the study was the confidentiality of the data. The Mobility Protocol Worksheets were collected daily and stored in a locked office. Once the Worksheets were used to obtain delirium information from the EMR, they were disposed of in appropriate locked shredding bins. The information obtained from the Worksheets and the EMR was de-identified and stored in Excel.

\section{Results}

\section{Nursing Education}

Before nursing education regarding the MICU's early mobility protocol was completed, a survey was sent to all MICU nurses via email. The survey was to assess baseline nursing knowledge of the unit's early mobility protocol and consisted of three questions: 1) Do you know about the MICU's Early Progressive Mobility Protocol (not the physician's order)? 2) Do you know where to locate the protocol? 3) Do you use the protocol in your daily practice? The survey had 31 respondents from the 95 nurses it was sent to. In response to the first question, $61 \%$ answered yes to knowing about the protocol. For the second question, $29 \%$ responded that they knew where to locate the protocol. Lastly, in response to the third question only $13 \%$ of respondents answered that they used the mobility protocol in their daily practice. This indicated to the researcher that education regarding the early mobility protocol needed to be conducted.

After the project was implemented and completed, the same survey was sent out to assess if there was a change in nursing knowledge and use of the mobility protocol. The follow-up survey had 15 respondents. In response to the first question, 93\% answered yes to knowing about the mobility protocol. For the second question, $80 \%$ of the respondents answered yes to 
knowing where to locate the protocol. Lastly, $36 \%$ of the respondents stated that they use the protocol in their daily practice.

\section{Delirium Outcomes}

Demographic and delirium data were compared between the two groups of subjects. The first group (pre-education group) consisted of 30 subjects who were admitted to the MICU before nursing education and project implementation. The post-education group consisted of 30 subjects who were mobilized using the MICU's early mobility protocol. Demographic data included age, race, gender, ICU LOS, and hospital LOS. In the MICU, delirium is assessed at least twice daily (day and night shift) using the CAM-ICU delirium assessment tool. Delirium was recorded as either positive or negative based on the patient's CAM-ICU score. Delirium data was collected in the pre-education group each day of their ICU admission. In the posteducation group, delirium data was collected each day starting from the day the patient was mobilized until their discharge from the ICU. The patient was considered negative for delirium if every CAM-ICU assessment was negative for that given day. If one assessment yielded a positive result, that patient would be recorded as delirium positive for the day. For each patient in the pre and post-education groups, the average percentage of delirium positive days were calculated for analysis.

The demographic data for each group is shown in Table 2. Additionally, a MannWhitney U test was run comparing ICU LOS and hospital LOS between the two groups. There was a statistically significant difference in ICU and hospital LOS when comparing the pre and post groups (median ICU LOS- pre-education 2.7 days versus post 6.0 days; $p=0.003$ and median hospital LOS- pre 5.5 days versus post 15.5 days; $\mathrm{p}=0.002$ ). While this was not an anticipated finding, reasons for these outcomes will be discussed below. 
As stated above, due to significant skewness, the delirium data for the pre and posteducation were compared using a Mann-Whitney U test. The median number of days that delirium data were collected was similar between the groups (pre 2.5 days versus post 3 days). The range of days varied between the two groups, but had the same interquartile range (pre 1-38 days, IQR 5 days versus post 1-17 days, IQR 5 days). The average number of delirium days for each patient in the pre and post-education groups were calculated. The median percentage of delirium positive days between the two groups was relatively similar (pre $14.6 \%$ versus post 0\%). A Mann-Whitney $\mathrm{U}$ test was run and showed that the difference between the two groups was not statistically significant $(\mathrm{p}=0.139)$. Results can be found in Table 3 .

Additionally analysis was run excluding patients in the post-eduation group who were mobilized the day of or the day before ICU discharge. It was believed that the mobility intervention was not likely to have an effect on delirium during the short time the patients remained in the ICU. In order to keep the two groups similar in size, the patients in the preeducation group with a one or two day ICU length of stay were also excluded. After exclusion, the pre-education group $n=18$ and the post-education group $n=15$. For these two groups, the median number of days that delirium data were collected was the same (median- pre 6 days versus post 6 days) The range and IQR varied between the two groups (range- pre 3-38 days versus post 3-17 days; IQR- pre 6 days versus post 8 days). Also, the average number of delirium positive days for each patient was calculated. Due to the normal distribution, an independent T-test was run on the groups. After analysis, there was a statistically significant difference between the two groups (mean (SD) pre $44.1 \%$ (35.2\%) versus post $20.5 \%(28.3 \%)$; $\mathrm{p}=0.045)$. Results can be found in Table 4 .

\section{Barriers to Mobilization}


The Early Mobility Worksheets included a place to document if the nurse was unable to mobilize a patient. This could have been because the patient failed the basic assessment, but also included a list of likely barriers to mobilizing patients in the ICU. During the project implementation, barriers to mobilization were identified on 81 occasions. The primary reason patients were not mobilized was that the patient failed the basic assessment. This accounted for 31 out of the 81 responses. Safety as a barrier to mobilization was reported in 25 of the 81 responses. Having enough time was identified on 10 occasions as a barrier to mobilization. Next, inadequate staffing was a barrier to mobilization in eight cases. For two patients, the barrier to mobilization was lack of equipment. Lastly, five patients or their families refused mobilization. Approaches to reduce these barriers are discussed below.

\section{Discussion}

\section{Nursing Education}

The need for nursing education regarding the MICU early mobility protocol was assessed using a survey sent out to all nursing staff on the unit. After receiving the results from the initial survey, it was clear that there was a nursing knowledge deficit about the early mobility protocol. The multi-faceted education process was systematic and appeared effective, but occurred over a relatively short period of time (two weeks). Given more time, all of the nursing staff would have received one-on-one education rather than just those who were working day shift. The same survey was sent out after project implementation to see if there was increased knowledge of the early mobility protocol. Only 15 nurses responded to the follow-up survey which was half the number of initial respondents. After education and project implementation, only $36 \%$ of the 15 respondents stated that they use the early mobility protocol in their daily practice. In the post survey, the responses demonstrated an increased knowledge about the protocol, but it did not 
show a significant increase in the use of the mobility protocol in daily practice. This could indicate the need for a different mobility protocol in the MICU. Perhaps one that is more userfriendly and easier to understand. It may also indicate the need for further education about the barriers nurses face when trying to mobilize patients and how to address those issues. Overall, it would be easier to extrapolate nursing education outcomes if more nurses were to respond to the surveys. In the future, it may be more effective to hand out a paper post-survey after education to increase compliance with completion.

\section{Delirium}

First, ICU and hospital length of stay were compared between the two groups. The difference between the groups for both ICU and hospital LOS were statistically significant. However, it was the opposite of the expected finding. The ICU and hospital LOS were significantly shorter for the pre-education group. One explanation for this finding is higher acuity illness in the post-education group patients. The data was collected during November and December which is typically when the unit sees an increase in the number of flu and pneumonia cases. Although, this may be the case no measure of acuity was collected for these patients. For future studies, the acuity of patients may be an important measurement to include.

Next, the delirium data were analyzed. When comparing both groups, the difference in the average number of days with delirium was not significantly different. However, when patients who were mobilized on the day of discharge or the day before discharge from the ICU were excluded the difference between the two groups became statistically significant. The posteducation group had less than half of the average delirium days when compared to the preeducation group. This indicates that the earlier patients are mobilized in the ICU the better the delirium outcomes. There are several reasons why patients may not be mobilized until the end of 
the ICU stay. First, patients may not be mobilizing earlier in their stay because nurses feel they are too sick to mobilize. Although there is an assessment in the mobility protocol to determine if a patient is safe to mobilize, nurses may feel that their knowledge of the patient's ability supersedes the assessment. Additionally, the nurses may feel more comfortable mobilizing patients when they are ready to leave the ICU because this indicates more stability. Also, nurses identified several barriers to mobilizing patients which may have prevented earlier mobility. This may indicate the need for more education and training about patients who are safe to mobilize and how to do it. In future studies, this would be an important to teach nurses that earlier mobility decreases delirium and to provide them with the tools to accomplish this.

It is also important to note that before implementation of this project another DNP project occurred that taught nurses about how to accurately document delirium using the CAM-ICU tool. The project occurred during the summer and fall before project implementation. The same staff was educated for both projects. This may have had an unforeseen impact on delirium data for this project. For future studies, it may be beneficial to provide education about CAM-ICU documentation.

\section{Barriers to Mobilization}

There were numerous barriers to mobilization identified by the nurses which highlight the need for practice changes in several areas. First, mobilization needs to be more highly prioritized in the daily care of MICU patients. In order to ensure patients are being mobilized safely, proper equipment should be readily available for all patients. As in Fraser, Spiva, Forman \& Hallen (2015), it may also be helpful for the MICU to develop a mobility team including a physical therapist, ICU nurse, and mobility technician. The implementation of a mobility team would hopefully eliminate barriers such as inadequate staffing and timing. Lastly, training staff 
on how to properly mobilize critically ill patients could help reduce the safety barriers. Overall, to decrease barriers to mobilization in the ICU, unit based leaders and staff must identify and prioritize areas for realistic improvement.

\section{Strengths and Limitations}

While many studies have shown the importance of mobilizing ICU patients, few have examined the impact of mobility interventions in reducing or preventing delirium. This study will contribute to the existing literature regarding the effectiveness of mobility protocols in reducing delirium. Limitations of this study include the lack of generalizability to other ICUs, data collection over a relatively short time period, and lack of randomization.

\section{Nursing Practice Implications}

This study will contribute to nursing knowledge about mobility protocols in the ICU, barriers to implementation, and delirium reduction with mobility. The study will add to the literature regarding mobility protocols reducing the incidence of delirium. Several nursing practice implication were identified as a result of this project. First, the need for a new mobility protocol in the MICU since nurses are still not frequently using the current protocol in their daily practice. The new protocol should be chosen in coordination with the nursing staff. The next nursing practice implication is the need for increased staffing to help with patient mobilization. Specifically, it would be helpful to have a patient care technician to serve as a mobility technician and an additional respiratory therapist specifically for mobilizing patients. Along with staffing, the unit should have more frequent physical therapy visits. Most patients with physical therapy consults are not seen every day and if they were it would drastically increase mobility. This would likely require hiring more physical therapists. Physical therapists could also hold educational meetings to teach the nursing staff how to safely mobilize ICU patients. 
This would increase the nurses' knowledge and confidence in mobilizing critically ill patients while also addressing safety concerns. Another area for improvement is easier access to equipment for mobilization. Each patient room should have a high back chair to safely mobilize patients out of bed. Additionally, there should be more access to bariatric equipment and passive transfer chairs. Currently, all 28 beds in the MICU share just a few pieces of equipment. If mobility is to become a priority, more equipment would need to be purchased. Lastly, as in Balas et al., (2014) it may be more effective to include mobility into a bundle like the ABCDE bundle. The implementation of this bundle would likely further improve delirium outcomes. 


\section{References}

Balas, M. C., Burke, W. J., Gannon, D., Cohen, M. Z., Colburn, L., Bevil, C., . . Vasilevskis, E. E. (2013). Implementing the awakening and breathing coordination, delirium monitoring/management, and early exercise/mobility bundle into everyday care: Opportunities, challenges, and lessons learned for implementing the ICU pain, agitation, and delirium guidelines. Critical Care Medicine, 41(9 Suppl 1), S116-27. doi:10.1097/CCM.0b013e3182a17064

Balas, M. C., Vasilevskis, E. E., Olsen, K. M., Schmid, K. K., Shostrom, V., Cohen, M. Z., ... Burke, W. J. (2014). Effectiveness and safety of the awakening and breathing coordination, delirium monitoring/management, and early exercise/mobility bundle*. Critical Care Medicine, 42(5), 1024-1036 13p. doi:10.1097/CCM.0000000000000129

Barr, J., Fraser, G. L., Puntillo, K., Ely, E. W., Gelinas, C., Dasta, J. F., . . American College of Critical Care Medicine. (2013). Clinical practice guidelines for the management of pain, agitation, and delirium in adult patients in the intensive care unit. Critical Care Medicine, 41(1), 263-306. doi:10.1097/CCM.0b013e3182783b72

Collinsworth, A. W., Priest, E. L. D. H., Campbell, C. R., Vasilevskis, E. E., \& Masica, A. L. M. S. C. I. (2016). A review of multifaceted care approaches for the prevention and mitigation of delirium in intensive care units. Journal of Intensive Care Medicine, 31(2), 127-141. doi:10.1177/0885066614553925

Donabedian, A. (1988). The quality of care. how can it be assessed? Jama, 260(12), 1743-1748. Retrieved from http://ovidsp.ovid.com.proxy.its.virginia.edu/ovidweb.cgi?T=JS\&CSC=Y\&NEWS=N\&PA $\mathrm{GE}=$ fulltext $\& \mathrm{D}=\mathrm{med} 3 \& \mathrm{AN}=3045356$ 
Early Mobility Toolkit. (2014). Retrieved June 29, 2016, from https://armstrongresearch.hopkinsmedicine.org/vap/vap/sessions.aspx

Ely, E. W., Margolin, R., Francis, J., May, L., Truman, B., Dittus, R., . . Inouye, S. K. (2001). Evaluation of delirium in critically ill patients: Validation of the confusion assessment method for the intensive care unit (CAM-ICU).Critical Care Medicine, 29(7), 1370-1379. Retrieved from http://ovidsp.ovid.com.proxy.its.virginia.edu/ovidweb.cgi?T=JS\&CSC=Y\&NEWS=N $\& P A G E=$ fulltext $\& D=\operatorname{med} 4 \& A N=11445689$

Foster, J., \& Kelly, M. (2013). A pilot study to test the feasibility of a nonpharmacologic intervention for the prevention of delirium in the medical intensive care unit. Clinical Nurse Specialist, 27(5), 231-238. doi:10.1097/NUR.0b013e3182a0b9f9

Fraser, D., Spiva, L., Forman, W., \& Hallen, C. (2015). Original research: Implementation of an early mobility program in an ICU. American Journal of Nursing, 115(12), 49-58. doi:10.1097/01.NAJ.0000475292.27985.fc

Hipp, D. M., \& Ely, E. W. (2012). Pharmacological and nonpharmacological management of delirium in critically ill patients. Neurotherapeutics, $9(1), 158-175$. doi:http://dx.doi.org.proxy.its.virginia.edu/10.1007/s13311-011-0102-9

Inouye, S. K., Bogardus, S. T. J., Williams, C. S., Leo-Summers, L., \& Agostini, J. V. (2003). The role of adherence on the effectiveness of nonpharmacologic interventions: Evidence from the delirium prevention trial. Archives of Internal Medicine, 163(8), 958-964.

Retrieved from http://ovidsp.ovid.com.proxy.its.virginia.edu/ovidweb.cgi?T=JS\&CSC=Y\&NEWS=N $\underline{\& P A G E}=$ fulltext $\& \mathrm{D}=$ med $4 \& \mathrm{AN}=12719206$ 
Needham, D. M., Korupolu, R., Zanni, J. M., Pradhan, P., Colantuoni, E., Palmer, J. B., .. . Fan, E. (2010). Early physical medicine and rehabilitation for patients with acute respiratory failure: A quality improvement project.Archives of Physical Medicine and Rehabilitation, 91(4), 536-542. doi:10.1016/j.apmr.2010.01.002

Norman, G. R., \& Streiner, D. L. (2003). PDQ statistics. Hamilton, Ont.: B.C. Decker.

O'Mahony, R., Murthy, L., Akunne, A., Young, J., \& Guideline Development Group. (2011). Synopsis of the national institute for health and clinical excellence guideline for prevention of delirium. Annals of Internal Medicine, 154(11), 746-751. doi:10.7326/0003-4819-154-11$\underline{201106070-00006}$

Schweickert, W. D., Pohlman, M. C., Pohlman, A. S., Nigos, C., Pawlik, A. J., Esbrook, C. L., . . . Kress, J. P. (2009). Early physical and occupational therapy in mechanically ventilated, critically ill patients: A randomised controlled trial. Lancet, 373(9678), 1874-1882. doi:10.1016/S0140-6736(09)60658-9 
Table 1.

Studies of mobility protocols with reported delirium outcomes

\begin{tabular}{|c|c|c|c|c|c|}
\hline Citation & Study Design \& Purpose & $\begin{array}{l}\text { Setting and } \\
\text { sample size }\end{array}$ & Intervention & Outcome Measures & Findings \\
\hline $\begin{array}{l}\text { Balas, et al., } \\
(2014) .\end{array}$ & $\begin{array}{l}\text { Prospective cohort study to } \\
\text { evaluate the safety and } \\
\text { effectiveness of } \\
\text { implementing the } \\
\text { Awakening and Breathing } \\
\text { coordination, Delirium } \\
\text { monitoring/management, } \\
\text { and Early exercise/mobility } \\
\text { bundle into everyday } \\
\text { practice }\end{array}$ & $\begin{array}{l}\text { Five adult ICUs, } \\
\text { one step-down unit } \\
\text { and one oncology } \\
\text { and hematology } \\
\text { special care unit } \\
\text { located in a 624- } \\
\text { bed tertiary } \\
\text { medical center } \\
\text { N=296 (146 pre- } \\
\text { bundle and } 150 \\
\text { post-bundle } \\
\text { implementation) }\end{array}$ & $\begin{array}{l}\text { Implementation of } \\
\text { Awakening and } \\
\text { Breathing } \\
\text { Coordination, } \\
\text { Delirium monitoring } \\
\text { and management, and } \\
\text { early } \\
\text { exercise/mobility } \\
\text { bundle }\end{array}$ & $\begin{array}{l}\text { Prevalence/duration } \\
\text { of delirium and } \\
\text { coma, early mobility, } \\
\text { mortality, time to } \\
\text { discharge, and } \\
\text { ventilator-free days }\end{array}$ & 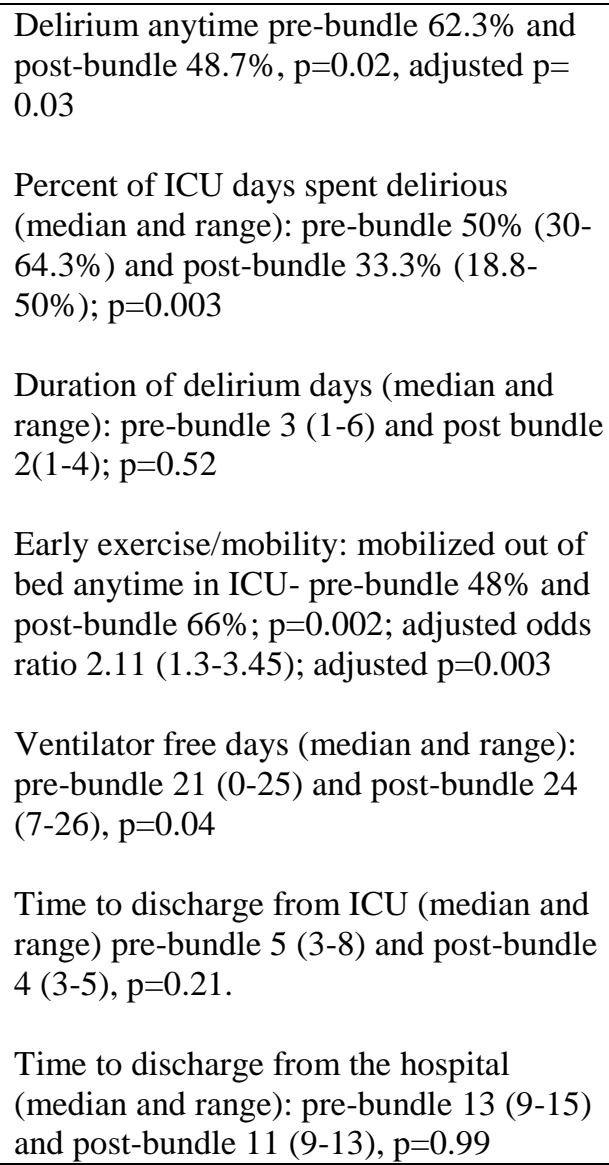 \\
\hline $\begin{array}{l}\text { Foster \& } \\
\text { Kelly } \\
(2013)\end{array}$ & $\begin{array}{l}\text { Prospective cohort pilot } \\
\text { study to determine the } \\
\text { feasibility of and test a }\end{array}$ & $\begin{array}{l}\text { A } 12 \text { bed medical } \\
\text { ICU in a magnet- } \\
\text { designated }\end{array}$ & $\begin{array}{l}\text { Multicomponent } \\
\text { intervention included: } \\
\text { daily sedation }\end{array}$ & $\begin{array}{l}\text { Delirium based on } \\
\text { CAM-ICU score }\end{array}$ & $\begin{array}{l}\text { Delirium data between the two groups was } \\
\text { not significantly different. From the } \\
\text { baseline data ( } 216 \text { delirium assessments), }\end{array}$ \\
\hline
\end{tabular}




\begin{tabular}{|c|c|c|c|c|c|}
\hline & $\begin{array}{l}\text { multicomponent, } \\
\text { nonpharmacological, } \\
\text { nurse-driven intervention } \\
\text { for prevention of delirium }\end{array}$ & $\begin{array}{l}\text { community } \\
\text { hospital in a } \\
\text { metropolitan in the } \\
\text { Southwest United } \\
\text { States } \\
\mathrm{N}=32\end{array}$ & $\begin{array}{l}\text { cessation, promotion } \\
\text { of sleep-wake cycles, } \\
\text { promotion of } \\
\text { meaningful sensory } \\
\text { stimulation, patient } \\
\text { mobility, and } \\
\text { preferred music } \\
\text { listening. }\end{array}$ & & $\begin{array}{l}28 \% \text { of screenings were positive for } \\
\text { delirium and } 12 \% \text { were unable to be } \\
\text { assessed. In the post-intervention data ( } 92 \\
\text { delirium screenings), } 31 \% \text { of delirium } \\
\text { assessments were positive for delirium and } \\
1 \% \text { were unable to be assessed. }\end{array}$ \\
\hline $\begin{array}{l}\text { Fraser, } \\
\text { Spiva, } \\
\text { Forman \& } \\
\text { Hallen } \\
(2015)\end{array}$ & $\begin{array}{l}\text { Prospective cohort pilot } \\
\text { study comparing ICU } \\
\text { patients who received } \\
\text { physical therapy from a } \\
\text { dedicated mobility team to } \\
\text { ICU patients who received } \\
\text { routine care. }\end{array}$ & $\begin{array}{l}3 \text { different ICUs in } \\
\text { an acute care } \\
\text { hospital in } \\
\text { Southeastern } \\
\text { United States } \\
\mathrm{N}=132\end{array}$ & $\begin{array}{l}\text { The formation of an } \\
\text { early mobility team } \\
\text { and mobility program }\end{array}$ & $\begin{array}{l}\text { Hospital LOS, ICU } \\
\text { LOS, duration of } \\
\text { mechanical } \\
\text { ventilation, days with } \\
\text { no delirium }\end{array}$ & 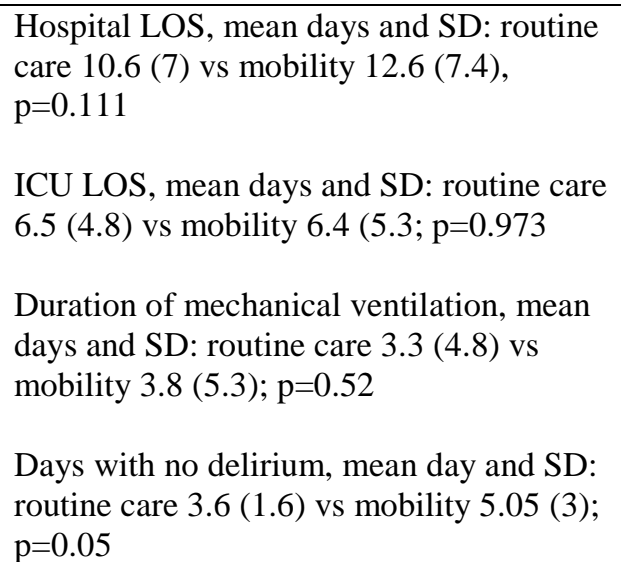 \\
\hline $\begin{array}{l}\text { Inouye, } \\
\text { Bogardus, } \\
\text { Williams, } \\
\text { Leo- } \\
\text { Summers \& } \\
\text { Agostini, } \\
(2003)\end{array}$ & $\begin{array}{l}\text { Prospective cohort pilot } \\
\text { study To examine the } \\
\text { impact of level of } \\
\text { adherence on effectiveness } \\
\text { of nonpharmacologic } \\
\text { interventions to prevent } \\
\text { delirium }\end{array}$ & $\begin{array}{l}\text { One general } \\
\text { medicine floor at } \\
\text { Yale New Haven } \\
\text { Hospital for March } \\
\text { 1995-March } 1998 \text {. } \\
\mathrm{N}=422\end{array}$ & $\begin{array}{l}\text { Implementation of } \\
\text { protocols specifically } \\
\text { targeted to manage } \\
\text { risk factors for } \\
\text { delirium. All patients } \\
\text { received orientation, } \\
\text { therapeutic activities, } \\
\text { and mobility } \\
\text { protocols. }\end{array}$ & $\begin{array}{l}\text { New onset delirium } \\
\text { during hospitalization } \\
\text { according to the } \\
\text { CAM-ICU criteria. } \\
\text { Adherence to the } \\
\text { intervention. }\end{array}$ & $\begin{array}{l}\text { Delirium was analyzed based on adherence } \\
\text { to protocol. Adherence groups were } \\
\text { divided into low, intermediate, and high. } \\
\text { For the mobility protocol, low adherence } \\
\text { was } 0 \% \text { to } 49 \% \text {, intermediate was } 50 \% \text { to } \\
74 \% \text {, and high was } 75 \% \text { to } 100 \% \text {. The rate } \\
\text { of delirium for each adherence group was } \\
\text { reported. For the low adherence group the } \\
\text { delirium rate was } 14 \% \text {, intermediate } 10 \% \text {, } \\
\text { and high } 3 \% \text {. The difference between the } \\
\text { groups was statistically significant with } \\
\text { p=0.01. }\end{array}$ \\
\hline $\begin{array}{l}\text { Needham } \\
\text { \&Korupolu } \\
(2010) .\end{array}$ & $\begin{array}{l}\text { A quality improvement } \\
\text { (QI) project to increase } \\
\text { rehabilitation-related } \\
\text { consults and treatments in } \\
\text { order to improve functional } \\
\text { mobility, to improve }\end{array}$ & $\begin{array}{l}\text { Johns Hopkins } \\
\text { Hospital's Medical } \\
\text { ICU (16 bed unit) } \\
\text { Pre-QI project } \\
n=27\end{array}$ & $\begin{array}{l}\text { A multidisciplinary } \\
\text { team focused on } \\
\text { reducing heavy } \\
\text { sedation and } \\
\text { increasing MICU } \\
\text { staffing to include }\end{array}$ & $\begin{array}{l}\text { Physical therapy } \\
\text { consultations, } \\
\text { proportion of ICU } \\
\text { days not delirious, } \\
\text { functional mobility, } \\
\text { MICU length of stay, }\end{array}$ & $\begin{array}{l}\text { Physical therapy consultations: pre-QI } \\
59 \% \text { and post-QI } 93 \% ; \mathrm{p}=0.004 \\
\text { Proportion of ICU days not delirious: pre- } \\
\text { QI } 21 \% \text { and post-QI } 53 \% \text {; }=0.003\end{array}$ \\
\hline
\end{tabular}




\begin{tabular}{|c|c|c|c|c|c|}
\hline & $\begin{array}{l}\text { patient sedation and } \\
\text { delirium status, and to } \\
\text { evaluate the effects on } \\
\text { length of stay }\end{array}$ & $\begin{array}{l}\text { Post-QI project } \\
n=30\end{array}$ & $\begin{array}{l}\text { full-time physical and } \\
\text { occupational } \\
\text { therapists with new } \\
\text { consultation } \\
\text { guidelines }\end{array}$ & $\begin{array}{l}\text { hospital length of } \\
\text { stay }\end{array}$ & $\begin{array}{l}\text { Functional mobility: pre-QI } 56 \% \text { and post- } \\
\text { QI } 78 \% ; p=0.03 \\
\text { MICU LOS, days: pre-QI } 7.0 \text { and post-QI } \\
4.9 ; \mathrm{p}=0.02 \\
\text { Hospital LOS, days: Pre-QI } 17.2 \text { and post- } \\
\text { QI } 14.1 ; \mathrm{p}=0.02\end{array}$ \\
\hline $\begin{array}{l}\text { Schweickert, } \\
\text { Pohlman, } \\
\text { Pohlman, } \\
\text { Nigos, } \\
\text { Pawlik, } \\
\text { Esbrook,... } \\
\text { Press (2009). }\end{array}$ & $\begin{array}{l}\text { Randomized control trial to } \\
\text { assess the efficacy of } \\
\text { combining daily } \\
\text { interruption of sedation } \\
\text { with physical and } \\
\text { occupational therapy on } \\
\text { functional outcomes in } \\
\text { patients receiving } \\
\text { mechanical ventilation in } \\
\text { intensive care. }\end{array}$ & $\begin{array}{l}\text { Medical ICUs of } \\
\text { University of } \\
\text { Chicago Medical } \\
\text { Center and } \\
\text { University of Iowa } \\
\text { Hospitals } \\
\text { N=104 adult } \\
\text { patients; } 49 \\
\text { intervention and } 55 \\
\text { control }\end{array}$ & $\begin{array}{l}\text { Daily physical and } \\
\text { occupational therapy } \\
\text { provided by physical } \\
\text { and occupational } \\
\text { therapists for patients } \\
\text { who have been } \\
\text { mechanically } \\
\text { ventilated for less } \\
\text { than } 72 \text { hours and } \\
\text { will remain ventilated } \\
\text { for the next } 24 \text { hours. }\end{array}$ & $\begin{array}{l}\text { ICU delirium (days), } \\
\text { time in ICU with } \\
\text { delirium }(\%) \text {, } \\
\text { ventilator free days, } \\
\text { duration of } \\
\text { mechanical } \\
\text { ventilation, ICU } \\
\text { LOS, hospital LOS }\end{array}$ & $\begin{array}{l}\text { ICU delirium (days): intervention } 2.0 \\
\text { versus control } 4.0 ; \mathrm{p}=0.03 \\
\text { Time in ICU with delirium (\%): } \\
\text { intervention } 33 \% \text { versus control } 57 \% \text {; } \\
\mathrm{p}=0.02 \\
\text { Ventilator-free days (of } 28 \text { days): } \\
\text { intervention } 23.5 \text { versus control } 21.1 ; \\
\mathrm{p}=0.05 \\
\text { Duration of mechanical ventilation (days): } \\
\text { intervention } 3.4 \text { versus control } 6.1 ; \mathrm{p}=0.02 \\
\text { ICU LOS (days): intervention } 5.9 \text { versus } \\
\text { control } 7.9 ; \mathrm{p}=0.08 \\
\text { Hospital LOS (days): intervention } 13.5 \\
\text { versus } 12.9 ; \mathrm{p}=0.93\end{array}$ \\
\hline
\end{tabular}


Table 2.

Demographic Data

\section{Pre-Education Group Post-Education Group}

\begin{tabular}{rcc}
\hline Sex (\% female) & $70 \%$ & $46.7 \%$ \\
Age, years (mean, SD) & $60.9(18.8)$ & $56.1(20.7)$ \\
Race (\%) & & \\
Caucasian & $80 \%$ & $80 \%$ \\
African American & $16.7 \%$ & $13.3 \%$ \\
Hispanic & $3.3 \%$ & $6.7 \%$ \\
ICU length of stay, days (median, range, IQR) & $2.7,1-37,5$ & $6,2-34,8$ \\
Hospital length of stay, days (median, range, IQR) & $5.5,1-48,8$ & $15.5,3-53,15$ \\
\hline
\end{tabular}


Table 3.

Delirium outcomes

\begin{tabular}{ccc} 
& Pre-Education & Post-Education \\
\hline Sample Size & $\mathrm{n}=30$ & $\mathrm{n}=30$ \\
$\begin{array}{c}\text { Median \% delirium } \\
\text { positive days }\end{array}$ & $14.6 \%$ & $0 \%$ \\
\hline
\end{tabular}

Mann-Whitney U test; $p=0.139$ 
Table 4.

Delirium outcomes excluding patients mobilized day of or day before ICU discharge

\begin{tabular}{ccc} 
& Pre-Education & Post-Education \\
\hline Sample Size & $\mathrm{n}=18$ & $\mathrm{n}=15$ \\
Mean \% Delirium Positive & $44.1 \%(35.2 \%)$ & $20.5 \%(28.3 \%)$ \\
Days (Standard Deviation) & & \\
\hline
\end{tabular}

Independent $\mathrm{T}$-test; $\mathrm{p}=0.045$ 


\section{Appendix A}

UVA IRB OnLine

University of Virginia

Institutional Review Board for Health Sciences Research

HIPAA Privacy Board

\begin{tabular}{|c|c|c|}
\hline \multicolumn{2}{|c|}{$\frac{\text { HIPAA Privacy Board }}{\text { IRB - HSR \# } 19359}$} & \\
\hline \multirow[t]{2}{*}{$\begin{array}{l}\text { Eveot: } \\
\text { Approval New Protocol - Expedited }\end{array}$} & \multirow[t]{2}{*}{$\begin{array}{l}\text { Typet } \\
\text { Protocol }\end{array}$} & $\begin{array}{l}\text { Sponear(t)i: } \\
\text { Spensor Protocel a: }\end{array}$ \\
\hline & & 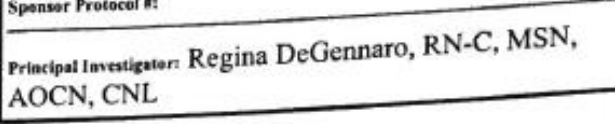 \\
\hline \multicolumn{3}{|c|}{ Tite: Early Mobility and its Effect on Delirium } \\
\hline \multicolumn{3}{|c|}{ Assurance: Federal Wide Assurance (FWA)\#: 00006183} \\
\hline \multicolumn{3}{|c|}{$\begin{array}{l}\text { Certification of IRB Review: The IRB-HSR/HIPAA Privacy Board abides by } 21 \text { CFR50, } 21 \text { CFR56, } \\
45 \text { CFR } 46,45 \text { CFR } 160,45 \text { CFR } 164,32 \text { CFR } 219 \text { and ICH guidelines. This activity has been reviewed in } \\
\text { accordance with these regulations. }\end{array}$} \\
\hline $\begin{array}{l}\text { Event Datr: } 11 / 10 / 16 \\
\text { Protoced Expiration Date: } 11 / 09 / 17 \\
\text { Namber of Subjects: } 175 \\
\text { HSR Protocol Verzioa Date: } 10 / 25 / 16 \\
\text { Dats Sectring Plan Date: } 11 / 01 / 16\end{array}$ & & \\
\hline \multicolumn{3}{|l|}{ Carreat States: Open to enrollment } \\
\hline \multicolumn{3}{|l|}{ Coasceat Version Datesi } \\
\hline \multicolumn{3}{|l|}{ Committee Membern (did mot vote): } \\
\hline \multirow{2}{*}{\multicolumn{3}{|c|}{$\begin{array}{l}\text { Committee Membern (did sot voto): } \\
\text { approved. } \\
\text { It is open to enrollment. }\end{array}$}} \\
\hline & & \\
\hline \multicolumn{3}{|c|}{$\begin{array}{l}\text { The purpose of this medical record review is to evaluate the effectiveness of an evidence based early } \\
\text { mobility clinical protocol to reduce the incidence and/or duration of delirium in the adult ICU setting. }\end{array}$} \\
\hline \multicolumn{3}{|c|}{$\begin{array}{l}\text { This research protocol will also identify barriers to implementing early mobility as defined per standard of } \\
\text { care. }\end{array}$} \\
\hline \multicolumn{3}{|c|}{ There is no outside sponsor for this study. } \\
\hline \multicolumn{3}{|l|}{$N=175$ subjects } \\
\hline \multicolumn{3}{|l|}{ Ages: greater than or equal to 18 years } \\
\hline \multicolumn{3}{|c|}{ The following documents were submitted with this protocol: mobility worksheet. } \\
\hline \multicolumn{3}{|c|}{ No additional committee approvals are required. } \\
\hline No compensation. & & \\
\hline
\end{tabular}

https://www.irb.virginia.edu/index.cfm?fuseAction=hsr_HTMLReports.reportProtocolAs... 11/10/2016 
UVA IRB OnLine

Page 2 of 3

REGULATORY INFORMATION:

The IRB determined this protocol met the criteria of minimal risk.

Protocol Expedited by Category \#5: Research involving materials (data, documents, records or specimens) that have been collected solely for non-research purposes (such as medical treatment and/or diagnosis).

This protocol has been granted a Waiver of Consent to identify potential subjects via 45CFR46.116.

This protocol has been granted a waiver of consent under 45CFR46.116 for the main study.

This protocol has been granted a waiver of HIPAA authorization under 45CFR 164.512(i)(2) for the main study.

The following HIPAA identifiers will be collected: name, all elements of dates, medical record number, account numbers, other information that could be used alone or in combination with other information to identify an individual.

The minimum necessary PHI to be collected includes: CAM-ICU scores (delirium information), Length of hospital and ICU stays, admitting diagnosis.

Subjects may not be contacted by any method (email, phone, in person etc.) to obtain more information for this study without additional IRB-HSR approval.

No identifiable health information will be taken or shared outside of the UVa HIPAA covered entity.

\section{PLEASE REMEMBER:}

* If an outside sponsor is providing funding or supplies, you must contact the SOM Grants and Contracts Office/ OSP regarding the need for a contract and letter of indemnification. If it is determined that either of these documents is required, participants cannot be enrolled until these documents are complete.

* You must notify the IRB of any new personnel working on the protocol PRIOR to them beginning work.

* You must obtain IRB approval prior to implementing any changes to the approved protocol or consent form except in an emergency, if necessary to safeguard the well-being of currently enrolled subjects.

* If you are obtaining consent from subjects, prisoners are not allowed to be enrolled in this study unless the IRB-HSR previously approved the enrollment of prisoners. If one of your subjects becomes a prisoner after they are enrolled in the protocol you must notify the IRB immediately.

* You must notify the IRB-HSR office within 30 days of the closure of this study.

* Continuation of this study past the expiration date requires re-approval by the IRB-HSR.

The IRB-HSR official noted below certifies that the information provided above is correct and that, as required, future reviews will be performed and certification will be provided.

\begin{tabular}{|c|c|}
\hline $\begin{array}{l}\text { Name: Margaret W. Ball, BSN, MEd, CIP } \\
\text { Tite: Member, Institutional Review Board for Health } \\
\text { Sciences Research } \\
\begin{array}{ll}\text { Phone: } 434-924-9634 & \text { Fax: } 434-924-2932\end{array}\end{array}$ & $\begin{array}{l}\text { Name and Address of Institution: } \\
\text { Institutional Review Board for Health Sciences } \\
\text { Research } \\
\text { PO Box } 800483 \\
\text { University of Virginia } \\
\text { Charlottesville, VA } 22908\end{array}$ \\
\hline $\begin{array}{l}\text { Approval: } \\
\text { Approved by Margaret W. Ball, BSN, MEd, CIP From IP A }\end{array}$ & $\begin{array}{l}\text { Date: } \\
11 / 10 / 16 \text { at } 03: 35 \mathrm{PM}\end{array}$ \\
\hline
\end{tabular}

https://www.irb.virginia.edu/index.cfm?fuseAction=hsr_HTMLReports.reportProtocolAs... 11/10/2016 


\section{Appendix B}
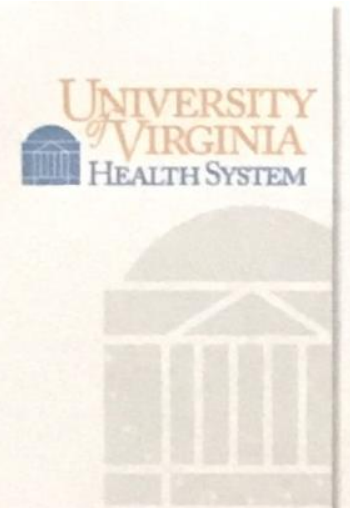

\section{The Medical Intensive Care UnIT}

June 15, 2016

Megan Boehling, RN, BSN, CCRN

Medical ICU

UVA Health System

\section{Megan,}

This letter represents permission given to you to conduct your DNP scholarly project on the implementation of early mobility to reduce the incidence of delirium in the Medical ICUs. Please let us know if we can be of further assistance.

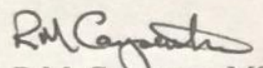

R.M. Carpenter, MSN, RN

Manager, Medical ICU

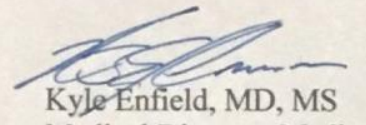

Medical Director, Medical ICU 
Appendix B

Early Mobility Protocol

\begin{tabular}{|c|c|c|c|c|c|}
\hline \multicolumn{2}{|c|}{ START HERE } & LEVEL 1 & LEVEL 2 & LEVEL 3 & LEVEL 4 \\
\hline \multirow{2}{*}{\multicolumn{2}{|c|}{$\begin{array}{l}\text { Initial Activity Screening } \\
\text { Within 24-hrs of admission }\end{array}$}} & $\begin{array}{l}\text { No / Low Cooperation } \\
\text { RASS - } 5 \text { to }-3\end{array}$ & $\begin{array}{c}\text { Moderate Cooperation } \\
\text { RASS }>-3 \text { to }-1\end{array}$ & $\begin{array}{c}\text { [Close to] Full cooperation } \\
\text { RASS }>-2 \text { to }-1\end{array}$ & $\begin{array}{c}\text { Full Cooperation } \\
\text { RASS }>0\end{array}$ \\
\hline & & $\begin{array}{c}\text { FAILS } \\
\text { BASIC ASSESSMENT }\end{array}$ & $\begin{array}{c}\text { PASSES } \\
\text { BASIC ASSESSMENT }\end{array}$ & $\begin{array}{c}\text { PASSES } \\
\text { BASIC ASSESSMENT }\end{array}$ & $\begin{array}{c}\text { PASSES } \\
\text { BASIC ASSESSMENT }\end{array}$ \\
\hline \multicolumn{6}{|c|}{ BASIC ASSESSMENT } \\
\hline \multicolumn{2}{|c|}{$\begin{array}{l}\text { Neurologic } \\
\text { RASS }>-3 \\
\text { Follows } 3-4 \text { commands }\end{array}$} & $\begin{array}{l}\text { BODY POSITIONING } \\
\text { - HOB }>30^{\circ} \\
\text { - Tuming Q } 2 \text { hours } \\
\text { - Splinting } \\
\text { - Consider specialty bed }\end{array}$ & $\begin{array}{l}\text { BODY POSIIIONING } \\
\text { - HOB }>30^{\circ} \\
\text { - Tuming Q } 2 \text { hours } \\
\text { - Splinting } \\
\text { - Progressive upright } \\
\text { mobility } \\
\text { - Passive transfer to chair }\end{array}$ & $\begin{array}{l}\text { BODY POSIIIONING } \\
\text { - HOB }>30^{\circ} \\
\text { - Splinting } \\
\text { - Passive transfer to chair } \\
\text { - Sitting out of bed } \\
\text { - Standing with assistance }\end{array}$ & $\begin{array}{l}\text { BODY POSITIONING } \\
\text { - HOB }>30^{\circ} \\
\text { - Splinting } \\
\text { - Active transfer to chair } \\
\text { - Sirting out of bed } \\
\text { - Standing with min. or } \\
\text { no assist }\end{array}$ \\
\hline \multicolumn{2}{|c|}{$\begin{array}{l}\text { Cardiovascular } \\
\text { HR }>50<140 \\
\text { MAP }>55<140 \\
\text { SBP }>90<200 \\
\text { No new or increasing } \\
\text { vasopressor infusion } \\
\text { No new arrhythmia }\end{array}$} & $\begin{array}{l}\quad \text { ACTIVITY } \\
\text { - Passive ROM } 2 \mathrm{x} \text { d } \\
\text { - Passive bed cycling } \\
\text { (Letto) }\end{array}$ & $\begin{array}{l}\quad \text { ACTIVITY } \\
\text { - Passive/active ROM } 2 \mathrm{x} \\
\text { d } \\
\text { - Resistance training (PT) } \\
\text { - Passive/active leg \&/or } \\
\text { amm cycling in bed } \\
\text { (Letto) or chair }\end{array}$ & $\begin{array}{l}\text { ACTIVITY } \\
\text { - Passive/active ROM } 2 x \\
\text { d } \\
\text { - Resistance training (PT) } \\
\text { - Active leg \& or arm } \\
\text { cycling in bed or chair } \\
\text { - Standing with assistance } \\
\text { - ADLs }\end{array}$ & $\begin{array}{l}\text { ACTIVITY } \\
\text { - Passive/active ROM } 2 \mathrm{x} \\
\text { d } \\
\text { - Resistance training (PT) } \\
\text { - Active leg \&/or anm } \\
\text { cycling in bed or chair } \\
\text { - Walking } \\
\text { - ADLs }\end{array}$ \\
\hline $\begin{array}{c}\text { FAIIS } \\
\text { Start level } 1\end{array}$ & $\begin{array}{l}\text { PASSES } \\
\text { Start level } 2\end{array}$ & $\begin{array}{c}\text { Tolerates level } 1 \\
\text { activities }\end{array}$ & $\begin{array}{l}\text { Tolerates level } 2 \\
\text { activities }\end{array}$ & $\begin{array}{c}\text { Tolerates level } 3 \\
\text { activities }\end{array}$ & $\begin{array}{l}\text { Ambulate progressively } \\
\text { longer distances }\end{array}$ \\
\hline \multicolumn{2}{|c|}{$\begin{array}{c}\text { PM \& R } \\
\text { CONSULTATIONS }\end{array}$} & OT: PROM / Splinting & $\begin{array}{l}\text { PT: If deconditioned } \\
\text { OT: PROM / splinting }\end{array}$ & $\begin{array}{l}\text { PT: If deconditioned } \\
\text { OT: ADL's / PROM } \\
\text { SLP: Cognitive }\end{array}$ & $\begin{array}{l}\text { PT: If deconditioned } \\
\text { OT: ADL's / PROM } \\
\text { SLP: cognitive }\end{array}$ \\
\hline
\end{tabular}


Appendix C

Early Mobility Worksheet

Date:

\section{Patient Label}

\begin{tabular}{|c|c|c|c|c|c|}
\hline \multicolumn{2}{|c|}{ START HERE } & LEVEL 1 & LBVBL 2 & LEVEL 3 & LEVEL 4 \\
\hline \multirow{2}{*}{\multicolumn{2}{|c|}{$\begin{array}{l}\text { Initial Activity Screening } \\
\text { Within 24-hrs of admission }\end{array}$}} & $\begin{array}{c}\text { No / Low Cooperation } \\
\text { RASS - } 5 \text { to }-3\end{array}$ & $\begin{array}{c}\text { Moderate Cooperation } \\
\text { RASS }>-3 \text { to }-1\end{array}$ & $\begin{array}{c}\text { [Close to] Full cooperation } \\
\text { RASS }>-2 \text { to }-1\end{array}$ & $\begin{array}{c}\text { Full Cooperation } \\
\qquad \text { RASS }>0\end{array}$ \\
\hline & & $\begin{array}{c}\text { FAILS } \\
\text { BASIC ASSESSMENT }\end{array}$ & $\begin{array}{c}\text { PASSES } \\
\text { BASIC ASSESSMENT }\end{array}$ & $\begin{array}{c}\text { PASSES } \\
\text { BASIC ASSESSMENT }\end{array}$ & $\begin{array}{c}\text { PASSES } \\
\text { BASIC ASSESSMENT }\end{array}$ \\
\hline \multicolumn{6}{|c|}{ BASIC ASSESSMENT } \\
\hline \multicolumn{2}{|c|}{$\begin{array}{l}\text { Neurologic } \\
\text { RASS }>-3 \\
\text { Follows } 3-4 \text { commands }\end{array}$} & $\begin{array}{l}\text { BODY POSIIIONING } \\
\text { - HOB }>30^{\circ} \\
\text { - Tuming Q } 2 \text { hours } \\
\text { - Splinting } \\
\text { - Consider specialry bed }\end{array}$ & $\begin{array}{l}\text { BODY POSIIIONIVG } \\
\text { - HOB }>30^{\circ} \\
\text { - Tuming } Q 2 \text { hours } \\
\text { - Splinting } \\
\text { - Progressive upright } \\
\text { mobility } \\
\text { - Passive transfer to chair }\end{array}$ & $\begin{array}{l}\text { BODY POSIIIONIIG } \\
\text { - HOB }>30^{\circ} \\
\text { - Splinting } \\
\text { - Passive transfer to chair } \\
\text { - Sirting cut of bed } \\
\text { - Standing with assistance }\end{array}$ & $\begin{array}{l}\text { BODY POSITIONING } \\
\text { - HOB }>30^{\circ} \\
\text { - Splinting } \\
\text { - Active transfer to chair } \\
\text { - Sirting out of bed } \\
\text { - Standing with min. or } \\
\text { no assist }\end{array}$ \\
\hline \multicolumn{2}{|c|}{$\begin{array}{l}\text { Cardiovascular } \\
\text { HR }>50<140 \\
\text { MAP }>55<140 \\
\text { SBP }>90<200 \\
\text { No new or increasing } \\
\text { vasopressor infusion } \\
\text { No new arrhythmia }\end{array}$} & $\begin{array}{l}\text { ACTIVTIY } \\
\text { - Passive ROM 2x d } \\
\text { - Passive bed cycling } \\
\text { (Letto) }\end{array}$ & $\begin{array}{l}\text { ACTIVITY } \\
\text { - Passive/active ROM 2x } \\
\text { d } \\
\text { - Resistance training (PT) } \\
\text { - Passive/active leg \&/or } \\
\text { arn cycling in bed } \\
\text { (Letto) or chair }\end{array}$ & $\begin{array}{l}\text { ACTIVTTY } \\
\text { - Passive active ROM } 2 \mathrm{x} \\
\text { d } \\
\text { - Resistance training (PT) } \\
\text { - Active leg \& or arm } \\
\text { cycling in bed or chair } \\
\text { - Standing with assistance } \\
\text { - ADLs }\end{array}$ & $\begin{array}{l}\text { ACTIVITY } \\
\text { - Passive active ROM } 2 \mathrm{~s} \\
\text { d } \\
\text { - Resistance training (PT) } \\
\text { - Active leg \&/or arm } \\
\text { cycling in bed or chair } \\
\text { - Walking } \\
\text { - ADLs }\end{array}$ \\
\hline $\begin{array}{l}\text { FAlls } \\
\text { Start level } 1\end{array}$ & $\begin{array}{l}\text { PASSES } \\
\text { Start level } 2\end{array}$ & $\begin{array}{l}\text { Tolerates level } 1 \\
\text { activities }\end{array}$ & $\begin{array}{c}\text { Tolerates level } 2 \\
\text { activities }\end{array}$ & $\begin{array}{c}\text { Tolerates level } 3 \\
\text { activities }\end{array}$ & $\begin{array}{l}\text { Ambulate progressively } \\
\text { longer distances }\end{array}$ \\
\hline \multicolumn{2}{|c|}{$\begin{array}{c}\text { PM 8R } \\
\text { CONSULTATIONS }\end{array}$} & OT: PROM / Splinting & $\begin{array}{l}\text { PT: If deconditioned } \\
\text { OT: PROM / splinting }\end{array}$ & $\begin{array}{l}\text { PT: If deconditioned } \\
\text { OT: ADL's / PROM } \\
\text { SLP: Cognitive }\end{array}$ & $\begin{array}{l}\text { PT: If deconditioned } \\
\text { OT: ADL's / PROM } \\
\text { SLP: cognitive }\end{array}$ \\
\hline
\end{tabular}

Was the patient mobilized?

If so, to what level?

If the patient was not mobilized, why? (circle one)

Pt. failed basic assessment $\quad \mathrm{Pt} /$ family refused $\quad$ Time $\quad$ Staffing $\quad$ Lack of equipment

Safety Other (comment) 
Appendix D

Reducing ICU Delirium by Promoting Early Mobility

Megan Ann Boehling MSN, RN, CCRN, AGACNP-BC Regina DeGennaro DNP, CNS, RN, AOCN, CNL

852 West Main St.

225 Jeanette Lancaster Way

Charlottesville, VA 22903

Charlottesville, VA 22908

\begin{abstract}
Megan Boehling is a registered nurse working in the MICU of UVA Medical Center. She is currently finishing her DNP program and plans to continue working in the MICU as a NP.

Dr. DeGennaro is the Academic Director for Clinical Partnerships at the School of Nursing. Her clinical research focuses on translating the evidence for oncology nursing practice to the bedside. Dr. DeGennaro serves as the Assistant Department Chair for the Department of Acute and Specialty Care at the School of Nursing.
\end{abstract} The authors of this paper had no financial information to disclose.

Thank you to UVA Medical Center, UVA MICU, UVA School of Nursing, Kyle Enfield, Rick Carpenter, and Regina DeGennaro for their help with this project.

Keywords: "early mobility", “delirium", “ICU”, “mobilization”, “CAM-ICU” 
Abstract

Delirium is described as an acute confusional state characterized by fluctuating mental status,

37 inattention, and either altered level of consciousness or disorganized thinking (Barr et al., 2013).

38 In the intensive care unit (ICU), delirium has been shown to occur in $60 \%$ to $80 \%$ of mechanically ventilated patients and $40 \%$ to $60 \%$ of nonventilated patients. According to the most recent Pain, Agitation, and Delirium (PAD) Clinical Practice Guidelines from the American College of Critical Care Medicine (2013), early mobility is recommended to reduce delirium

42 Project Purpose: The purpose of the project was to educate nurses about the implementation of an evidence based early mobility protocol to reduce the incidence of delirium in the adult ICU

44 setting. The project also identified barriers to implementing early mobility protocols.

45 Method: A quality improvement project included a five-step approach; 1) assessed current nursing knowledge about early mobility and protocol implementation; 2) educated unit-based

47 critical care nurses about the early mobility protocol; 3) provided nurses with an Early Mobility

48 Worksheet for documentation of protocol implementation; 4) accessed the electronic medical record of those patients mobilized and trended delirium; 5) The delirium data was compared to

50 the baseline group (pre-education) to identify if there was a reduction in delirium

51 Results: Analysis was run excluding patients in the post-education group who were mobilized

52 the day of or the day before ICU discharge. It was felt that the mobility intervention was not

53 likely have an effect on delirium during the short time the patients remained in the ICU. After

54 analysis, there was a statistically significant difference between the two groups (mean (SD) pre

$55 \quad 44.1 \%(35.2 \%)$ versus post $20.5 \%(28.3 \%) ; \mathrm{p}=0.045)$.

56 Discussion: The findings indicate that the earlier patients are mobilized in the ICU the better the 57 delirium outcomes. 


\section{Reducing ICU Delirium by Promoting Early Mobility}

\section{Background}

Delirium is described in the Diagnostic and Statistical Manual of Mental DisordersFourth Edition (Text Revision) (DSM IV-TR) as an acute confusional state characterized by fluctuating mental status, inattention, and either altered level of consciousness or disorganized thinking. In the intensive care unit (ICU), delirium has been shown to occur in $60 \%$ to $80 \%$ of mechanically ventilated patients and $40 \%$ to $60 \%$ of nonventilated patients. Delirium can be subcategorized based on the patient's level of alertness into hyperactive, hypoactive, and mixed delirium. The hypoactive subtype is the most common accounting for $60 \%$ of delirium cases. Risk factors for delirium can be divided into three categories: 1) characteristics of acute illness, 2) patient or host factors, and 3) environmental or iatrogenic factors. While the risk factors for delirium are numerous, some of the more common causes include sedative, opiate, and benzodiazepine medications, age (greater than 65 years), sleep deprivation, immobilization, infection, and underlying dementia or previous delirium (Hipp \& Ely, 2012). The most commonly used tool for monitoring delirium in the ICU is the Confusion Assessment Method for the Intensive Care Unit (CAM-ICU). This tool has high sensitivity (93-100\%), high specificity (98-100\%), and high inter-rater reliability (kappa=0.96). The CAM-ICU is often used in combination with the Richmond Agitation-Sedation Score (RASS) or the Riker SedationAgitation Scale (SAS) (Hipp \& Ely, 2012). Delirium is important to identify and treat, because long term consequences including cognitive deficits and severe weakness lead to additional costs of \$2500 per patient or \$6.9 billion annually (O’Mahony, Murthy, Akunne \&Young, 2011).

According to the most recent clinical practice guidelines from the American College of Critical Care Medicine (2013), there are a few ways to prevent and treat delirium. Early mobility 
82 is recommended to reduce the incidence and duration of delirium. Pharmacologic prevention is

83 not recommended because there is no compelling data to demonstrate that it reduces the

84 incidence or duration of delirium (Barr et al., 2013). Delirium treatment and prevention is

85 commonly included in a care bundle which are several interventions that together are shown to

86 improve critically-ill patient's outcomes. One of the most common care bundles is the

87 Awakening and Breathing Coordination, Delirium monitoring/management, and Early exercise/mobility (ABCDE bundle). This bundle is an example of an interprofessional evidence-

89 based multicomponent ICU management strategy aimed at reducing sedation exposure, duration 90 of mechanical ventilation, and ICU-acquired delirium and weakness (Balas et al., 2013). Based

91 on this information, a literature review was performed to determine the effect of mobility

92 protocols on the incidence and duration of delirium.

\section{Literature Review}

A literature review was performed to determine if early mobility protocols reduce the incidence or duration of delirium in adult ICU patients. Key terms searched were: "delirium," "intensive care unit" or "ICU," "early mobility" or "early ambulation” or "physical therapy" or

97 "rehabilitation." The inclusion criteria for articles were qualitative or quantitative studies of delirium outcomes, studies with implementation of a mobility protocol, reports secondary data

99 including ICU and hospital length of stay (LOS) and ventilator-free days. Exclusion criteria 100 were articles before 2000, published in language other than English, studies that do not report 101 delirium outcome data, and studies that do not implement a mobility protocol. For the review of 102 literature, eight articles were retained. 
105 hypothesis that early mobility protocols reduce the incidence and duration of delirium.

106 Collinsworth et al., (2016) found that multifaceted care approaches that included mobility were 107 associated with significant reductions in the incidence of delirium, duration of delirium, or days 108 patients spent awake and not delirious. Schweickert et al., (2009) demonstrated in a randomized 109 control trial that implementing physical and occupational therapy for intubated ICU patients 110 reduced the duration of delirium. Lastly, five of the six prospective cohort studies reported that 111 early mobility decreased the incidence and/or the duration of delirium. Overall, the review of

112 literature reveals that mobility is an effective intervention for reducing the incidence and 113 duration of delirium.

\section{Methods}

According to the American College of Critical Care Medicine (2013), early mobility is the primary nonpharmacological recommendation for reducing the incidence and duration of

117 delirium. Based on the literature review, an educational project was conducted MICU (setting) to 118 determine the effectiveness of an early mobility protocol on reducing the incidence of delirium.

119 The project included a five-step approach; 1) assessed current nursing knowledge about early

120 mobility and protocol implementation in the critical care unit; 2) educated unit-based critical care 121 nurses about the early mobility protocol and its significance in patient care; 3) provided nurses 122 with an Early Mobility Worksheet for documentation of protocol implementation; 4) accessed 123 the electronic medical record of those patients mobilized and trended delirium data while patient 124 remained in the ICU; 5) the delirium data was compared to the pre-education group (pre group) 125 to identify if there was a reduction in delirium incidence.

\section{Purpose of the study}


The purpose of the project was to educate nurses about the implementation of an

128

evidence based early mobility protocol to reduce the incidence of delirium in the adult ICU setting. The project also identified barriers to implementing early mobility protocols. This project was designed to increase nursing knowledge regarding early mobility, encourage mobilization in intensive care patients, to decrease the incidence of delirium, and to identify barriers to early mobilization in the intensive care setting.

\section{Hypothesis}

Educating nurses about the implementation of an evidence based early mobility protocol will reduce the incidence of delirium in an adult MICU.

\section{Research Design}

This study was a quality improvement project with a retrospective pre-post cohort design.

\section{Sample}

Data for the study was obtained through patient charts via the electronic medical record (EMR). The sample was MICU patients deemed eligible by the protocol to receive early mobility. The sample data was gathered over a one month time period to achieve a sample size of 30 ( $n=30)$. Inclusion criteria included: adult MICU patients (over 18 years of age) and patient admitted to the MICU for more than 24 hours. Exclusion criteria included: inability to follow commands, RASS score of -3 or less, mechanical ventilation with positive end-expiratory pressure (PEEP) greater than 10, oxygen supplementation with greater than $70 \%$ fraction of inspired oxygen (FiO2), respiratory rate less than 5 or greater than 40 breaths per minute, heart rate less than 50 or greater than 140 beats per minute, mean arterial pressure (MAP) less than 55 or greater than 140, systolic blood pressure (SBP) less than 90 or greater than 200 , new or increasing vasopressor infusions or new cardiac arrhythmia. 


\section{$150 \quad$ Setting}

The setting for the study was the MICU of a large academic medical center in the Southeast United States. The MICU is a 28 bed unit within the roughly 600 bed medical center. Approval for study implementation in the MICU was granted by the medical director and nurse manager of the unit. The Human Subjects Research IRB approved the study protocol (Appendix A).

\section{Nursing Knowledge and Education}

Nursing knowledge about the evidence based early mobility protocol and its significance in patient care was assessed using an anonymous survey prior to nursing education. The survey was sent out via e-mail, returned via email on the secure server, and the results were stored in Excel. The education of the critical care nurses was multi-faceted. First, information regarding the evidence based early mobility protocol and its importance in patient care was sent out to all medical intensive care nurses via email. The email also had supporting evidence from the most recent Pain, Agitation, and Delirium (PAD) Clinical Practice Guidelines from the American College of Critical Care Medicine (2013). Information regarding project implementation and the Early Mobility Worksheet was also sent out to familiarize the nurses with the format. The same information was presented at the MICU staff meeting which occurs the first Tuesday of every month. Lastly, one-on-one education was provided on the unit the week before project implementation. One-on-one education was provided to all nurses during day shift for seven consecutive days. While education was occurring, the unit staffed 95 nurses. Of those nurses, 65 received one-on-one education. The 30 nurses who did not receive one-on-one education were working night shift and the project was designed to be implemented during day shift. The 
172 researcher was also available throughout project implementation to respond to the staff's

173 questions.

\section{The Early Mobility Protocol}

175 The early mobility protocol was adapted from Johns Hopkins Armstrong Institute for 176 Patient Safety and Quality’s Early Mobility Toolkit (Early Mobility Toolkit, 2014) (Appendix B).

177 The early mobility protocol consisted of a patient assessment and progressive levels of mobility.

178 If the patient passed the assessment (stated in inclusion and exclusion criteria above), then

179 progressive mobility was started based on patient ability. The progressive mobility consisted of

180 four levels. The first level consisted of turning the patient in bed every two hours and passive

181 range of motion. Level two included passive transfer to chair or chair position in bed. Level

182 three included standing with assistance or sitting out of bed. Level four consisted of active

183 transfer to chair, standing with minimum or no assistance, and ambulating.

184 The early mobility protocol first required identification of the patients who were eligible 185 for mobilization. The initial activity screening was performed for all patients within 24 hours of 186 admission to the ICU. This initial screening was performed during interdisciplinary rounds.

187 After orders were placed for the mobility protocol, the bedside nurse performed a basic 188 assessment to determine if mobilizing the patient was safe and appropriate. The basic 189 assessment determined neurologic, respiratory, and cardiovascular stability. The patient failed 190 the basic assessment if any of the exclusion criteria (above) were met. If the patient failed the 191 assessment, the patient only received mobility level one until stabilized. The patients who 192 passed the basic assessment were mobilized starting at level two and progressed based on patient 193 ability. After the patient was mobilized, the nurse documented the mobility level reached on the 194 Mobility Protocol Worksheet (described below). 


\section{Procedure}

After determining which patients were mobilized, the patient medical records were accessed via the EMR by the researcher. The data were obtained manually from the EMR for each patient. For each patient mobilized, the CAM-ICU score was obtained starting with the first day mobilized until the patient was discharged from the ICU. The data were collected from the Mobility Protocol Worksheet and the EMR. The Mobility Protocol Worksheets were collected daily and stored in a locked office. After collection, data were de-identified and organized using Excel. The worksheets were disposed of in appropriate shred bins.

The mobility data was compared to a pre-education group obtained before nursing education regarding mobility protocol implementation. The pre-education data were collected on thirty random patients starting on September 1, 2016. The data were obtained by information technology experts from the medical center. The data were de-identified and stored in Excel.

\section{Measures}

Demographic data were obtained from the EMR and included age, gender, ICU LOS, and hospital LOS. Delirium data were obtained for those patients who were mobilized using the Mobility Protocol Worksheet (Appendix C). The worksheet was a quality improvement data collection instrument that was paired with EMR delirium data. First, there were places for the date and a patient information label. Next, the early mobility protocol was on the worksheet as a reminder for the nurses. Below the mobility protocol illustration, there were two questions.

First, was the patient mobilized to a level greater than level one? The next question: If not, why? The worksheet had options to choose between to respond to the question including: patient failed basic assessment, patient/family refused, time, staffing, lack of equipment, safety, other (comment). The nurse was asked to circle one of the options. An example of the Mobility 
218 Protocol Worksheet is in an appendix below (Appendix C). Delirium was measured using the

219 CAM-ICU tool. This measure has high sensitivity (93-100\%), high specificity (98-100\%), and

220 high inter-rater reliability (kappa=0.96) (Ely et al., 2001).

221 Data Analysis

222 The data were analyzed using the statistical package SPSS version 24. Demographic data 223 were analyzed using descriptive statistics such as means, percentages, and frequencies. Due to 224 the skewness of the ICU and hospital LOS data, medians and interquartile range (IQR) were used 225 to describe the data. To test for a statistically significant difference between the pre and post226 education groups' length of stays, a Mann-Whitney U test was performed. Statistical analysis for 227 the delirium data was run in two ways. First, the average number of delirium positive days was 228 calculated for each patient in the pre and post group. Due to skewness of the pre and post 229 delirium data, a Mann-Whitney U test was performed to analyze for a statistically significant 230 difference between the two groups. Additionally, before any analysis was performed, it was 231 noted that many patients in the post-education group were mobilized on the day of or the day 232 before discharge. It was believe that the mobility intervention was not likely to have an effect on 233 delirium for these patients due to the short period of time the patient remained in the ICU.

234 Therefore, an additional analysis was performed excluding the patients who were mobilized the 235 day of or the day before ICU discharge. The patients in the pre group with only one or two day 236 ICU stays were also excluded. An independent-t test was run comparing the two groups to test 237 for statistical significance. (Norman \& Streiner, 2003).

238 Protection of Human Subjects

The appropriate IRB application was submitted and approved. The risk of the study was 240 the confidentiality of the data. The Mobility Protocol Worksheets were collected daily and 
241 stored in a locked office. Once the Worksheets were used to obtain delirium information from

242 the EMR, they were disposed of in appropriate locked shredding bins. The information obtained

243 from the Worksheets and the EMR was de-identified and stored in Excel.

Results

245 Nursing Education

246 Before nursing education regarding the MICU's early mobility protocol was completed, a

247 survey was sent to all MICU nurses via email. The survey was to assess baseline nursing

248 knowledge of the unit's early mobility protocol and consisted of three questions: 1) Do you

249 know about the MICU's Early Progressive Mobility Protocol (not the physician's order)? 2) Do

250 you know where to locate the protocol? 3) Do you use the protocol in your daily practice? The

251 survey had 31 respondents from the 95 nurses it was sent to. In response to the first question,

$25261 \%$ answered yes to knowing about the protocol. For the second question, $29 \%$ responded that

253 they knew where to locate the protocol. Lastly, in response to the third question only $13 \%$ of

254 respondents answered that they used the mobility protocol in their daily practice. This indicated

255 to the researcher that education regarding the early mobility protocol needed to be conducted.

256 After the project was implemented and completed, the same survey was sent out to assess

257 if there was a change in nursing knowledge and use of the mobility protocol. The follow-up

258 survey had 15 respondents. In response to the first question, 93\% answered yes to knowing

259 about the mobility protocol. For the second question, $80 \%$ of the respondents answered yes to

260 knowing where to locate the protocol. Lastly, 36\% of the respondents stated that they use the

261 protocol in their daily practice.

262 Delirium Outcomes 
Demographic and delirium data were compared between the two groups of subjects. The

264 first group (pre-education group) consisted of 30 subjects who were admitted to the MICU

265 before nursing education and project implementation. The post-education group consisted of 30

266 subjects who were mobilized using the MICU's early mobility protocol. Demographic data

267 included age, race, gender, ICU LOS, and hospital LOS. In the MICU, delirium is assessed at

268 least twice daily (day and night shift) using the CAM-ICU delirium assessment tool. Delirium

269 was recorded as either positive or negative based on the patient's CAM-ICU score. Delirium

270 data was collected in the pre-education group each day of their ICU admission. In the post-

271 education group, delirium data was collected each day starting from the day the patient was

272 mobilized until their discharge from the ICU. The patient was considered negative for delirium

273 if every CAM-ICU assessment was negative for that given day. If one assessment yielded a

274 positive result, that patient would be recorded as delirium positive for the day. For each patient

275 in the pre and post-education groups, the average percentage of delirium positive days were 276 calculated for analysis.

277 The demographic data for each group is shown in Table 2. Additionally, a Mann-

278 Whitney U test was run comparing ICU LOS and hospital LOS between the two groups. There

279 was a statistically significant difference in ICU and hospital LOS when comparing the pre and

280 post groups (median ICU LOS- pre-education 2.7 days versus post 6.0 days; $\mathrm{p}=0.003$ and median

281 hospital LOS- pre 5.5 days versus post 15.5 days; $\mathrm{p}=0.002$ ). While this was not an anticipated

282 finding, reasons for these outcomes will be discussed below.

283 As stated above, due to significant skewness, the delirium data for the pre and post-

284 education were compared using a Mann-Whitney $U$ test. The median number of days that

285 delirium data were collected was similar between the groups (pre 2.5 days versus post 3 days). 
286 The range of days varied between the two groups, but had the same interquartile range (pre 1-38

287

288

289

290

291

292

293

294

295

296

297

298

299

300

301

302

303

304

305

306

307

308 days, IQR 5 days versus post 1-17 days, IQR 5 days). The average number of delirium days for

each patient in the pre and post-education groups were calculated. The median percentage of delirium positive days between the two groups was relatively similar (pre $14.6 \%$ versus post 0\%). A Mann-Whitney U test was run and showed that the difference between the two groups was not statistically significant $(\mathrm{p}=0.139)$. Results can be found in Table 3 .

Additionally analysis was run excluding patients in the post-eduation group who were mobilized the day of or the day before ICU discharge. It was believed that the mobility intervention was not likely to have an effect on delirium during the short time the patients remained in the ICU. In order to keep the two groups similar in size, the patients in the preeducation group with a one or two day ICU length of stay were also excluded. After exclusion, the pre-education group $n=18$ and the post-education group $n=15$. For these two groups, the median number of days that delirium data were collected was the same (median- pre 6 days versus post 6 days) The range and IQR varied between the two groups (range- pre 3-38 days versus post 3-17 days; IQR- pre 6 days versus post 8 days). Also, the average number of delirium positive days for each patient was calculated. Due to the normal distribution, an independent T-test was run on the groups. After analysis, there was a statistically significant difference between the two groups (mean (SD) pre $44.1 \%$ (35.2\%) versus post $20.5 \%$ (28.3\%); $\mathrm{p}=0.045)$. Results can be found in Table 4 .

\section{Barriers to Mobilization}

The Early Mobility Worksheets included a place to document if the nurse was unable to mobilize a patient. This could have been because the patient failed the basic assessment, but also included a list of likely barriers to mobilizing patients in the ICU. During the project 
309 implementation, barriers to mobilization were identified on 81 occasions. The primary reason 310 patients were not mobilized was that the patient failed the basic assessment. This accounted for

31131 out of the 81 responses. Safety as a barrier to mobilization was reported in 25 of the 81 312 responses. Having enough time was identified on 10 occasions as a barrier to mobilization. 313 Next, inadequate staffing was a barrier to mobilization in eight cases. For two patients, the 314 barrier to mobilization was lack of equipment. Lastly, five patients or their families refused 315 mobilization. Approaches to reduce these barriers are discussed below.

\section{Discussion}

\section{Nursing Education}

The need for nursing education regarding the MICU early mobility protocol was assessed using a survey sent out to all nursing staff on the unit. After receiving the results from the initial survey, it was clear that there was a nursing knowledge deficit about the early mobility protocol. The multi-faceted education process was systematic and appeared effective, but occurred over a relatively short period of time (two weeks). Given more time, all of the nursing staff would have received one-on-one education rather than just those who were working day shift. The same survey was sent out after project implementation to see if there was increased knowledge of the early mobility protocol. Only 15 nurses responded to the follow-up survey which was half the number of initial respondents. After education and project implementation, only $36 \%$ of the 15 respondents stated that they use the early mobility protocol in their daily practice. In the post survey, the responses demonstrated an increased knowledge about the protocol, but it did not show a significant increase in the use of the mobility protocol in daily practice. This could indicate the need for a different mobility protocol in the MICU. Perhaps one that is more userfriendly and easier to understand. It may also indicate the need for further education about the 
332 barriers nurses face when trying to mobilize patients and how to address those issues. Overall, it 333 would be easier to extrapolate nursing education outcomes if more nurses were to respond to the 334 surveys. In the future, it may be more effective to hand out a paper post-survey after education 335 to increase compliance with completion.

Delirium

First, ICU and hospital length of stay were compared between the two groups. The difference between the groups for both ICU and hospital LOS were statistically significant. However, it was the opposite of the expected finding. The ICU and hospital LOS were significantly shorter for the pre-education group. One explanation for this finding is higher acuity illness in the post-education group patients. The data was collected during November and December which is typically when the unit sees an increase in the number of flu and pneumonia cases. Although, this may be the case no measure of acuity was collected for these patients. For

344 future studies, the acuity of patients may be an important measurement to include.

Next, the delirium data were analyzed. When comparing both groups, the difference in

346 the average number of days with delirium was not significantly different. However, when

347 patients who were mobilized on the day of discharge or the day before discharge from the ICU

348 were excluded the difference between the two groups became statistically significant. The post-

349 education group had less than half of the average delirium days when compared to the pre-

350 education group. This indicates that the earlier patients are mobilized in the ICU the better the

351 delirium outcomes. There are several reasons why patients may not be mobilized until the end of 352 the ICU stay. First, patients may not be mobilizing earlier in their stay because nurses feel they 353 are too sick to mobilize. Although there is an assessment in the mobility protocol to determine if 354 a patient is safe to mobilize, nurses may feel that their knowledge of the patient's ability 
355 supersedes the assessment. Additionally, the nurses may feel more comfortable mobilizing

356 patients when they are ready to leave the ICU because this indicates more stability. Also, nurses

357 identified several barriers to mobilizing patients which may have prevented earlier mobility.

358 This may indicate the need for more education and training about patients who are safe to

359 mobilize and how to do it. In future studies, this would be an important to teach nurses that

360 earlier mobility decreases delirium and to provide them with the tools to accomplish this.

361 Barriers to Mobilization

There were numerous barriers to mobilization identified by the nurses which highlight the need for practice changes in several areas. First, mobilization needs to be more highly

364 prioritized in the daily care of MICU patients. In order to ensure patients are being mobilized 365 safely, proper equipment should be readily available for all patients. As in Fraser, Spiva, Forman 366 \& Hallen (2015), it may also be helpful for the MICU to develop a mobility team including a 367 physical therapist, ICU nurse, and mobility technician. The implementation of a mobility team 368 would hopefully eliminate barriers such as inadequate staffing and timing. Lastly, training staff 369 on how to properly mobilize critically ill patients could help reduce the safety barriers. Overall, 370 to decrease barriers to mobilization in the ICU, unit based leaders and staff must identify and 371 prioritize areas for realistic improvement.

372 Strengths and Limitations

373 While many studies have shown the importance of mobilizing ICU patients, few have 374 examined the impact of mobility interventions in reducing or preventing delirium. This study 375 will contribute to the existing literature regarding the effectiveness of mobility protocols in 376 reducing delirium. Limitations of this study include the lack of generalizability to other ICUs, 377 data collection over a relatively short time period, and lack of randomization. 

delirium outcomes.

This study will contribute to nursing knowledge about mobility protocols in the ICU, barriers to implementation, and delirium reduction with mobility. The study will add to the literature regarding mobility protocols reducing the incidence of delirium. Several nursing practice implications were identified as a result of this project. First, the need for a new mobility protocol in the MICU since nurses are still not frequently using the current protocol in their daily practice. The new protocol should be chosen in coordination with the nursing staff. The next nursing practice implication is the need for increased staffing to help with patient mobilization. Specifically, it would be helpful to have a patient care technician to serve as a mobility technician and an additional respiratory therapist specifically for mobilizing patients. Along with staffing, the unit should have more frequent physical therapy visits. Most patients with physical therapy consults are not seen every day and if they were it would drastically increase mobility. Physical therapists could also hold educational meetings to teach the nursing staff how to safely mobilize ICU patients. This would increase the nurses' knowledge and confidence in mobilizing critically ill patients while also addressing safety concerns. Another area for improvement is easier access to equipment for mobilization. Each patient room should have a high back chair to safely mobilize patients out of bed. Additionally, there should be more access to bariatric equipment and passive transfer chairs. Currently, all 28 beds in the MICU share just a few pieces of equipment. If mobility is to become a priority, more equipment would need to be purchased. Lastly, as in Balas et al., (2014) it may be more effective to include mobility into a bundle like the ABCDE bundle. The implementation of this bundle would likely further improve 


\section{References}

Balas, M. C., Burke, W. J., Gannon, D., Cohen, M. Z., Colburn, L., Bevil, C., . . Vasilevskis, E. E. (2013). Implementing the awakening and breathing coordination, delirium monitoring/management, and early exercise/mobility bundle into everyday care: Opportunities, challenges, and lessons learned for implementing the ICU pain, agitation, and delirium guidelines. Critical Care Medicine, 41(9 Suppl 1), S116-27. doi:10.1097/CCM.0b013e3182a17064

Balas, M. C., Vasilevskis, E. E., Olsen, K. M., Schmid, K. K., Shostrom, V., Cohen, M. Z., ... Burke, W. J. (2014). Effectiveness and safety of the awakening and breathing coordination, delirium monitoring/management, and early exercise/mobility bundle*. Critical Care Medicine, 42(5), 1024-1036 13p. doi:10.1097/CCM.0000000000000129

Barr, J., Fraser, G. L., Puntillo, K., Ely, E. W., Gelinas, C., Dasta, J. F., . . American College of Critical Care Medicine. (2013). Clinical practice guidelines for the management of pain, agitation, and delirium in adult patients in the intensive care unit. Critical Care Medicine, 41(1), 263-306. doi:10.1097/CCM.0b013e3182783b72

Collinsworth, A. W., Priest, E. L. D. H., Campbell, C. R., Vasilevskis, E. E., \& Masica, A. L. M. S. C. I. (2016). A review of multifaceted care approaches for the prevention and mitigation of delirium in intensive care units. Journal of Intensive Care Medicine, 31(2), 127-141. doi:10.1177/0885066614553925

Donabedian, A. (1988). The quality of care. how can it be assessed? Jama, 260(12), 1743-1748. Retrieved from http://ovidsp.ovid.com.proxy.its.virginia.edu/ovidweb.cgi?T=JS\&CSC=Y\&NEWS=N\&PA $\mathrm{GE}=$ fulltext $\& \mathrm{D}=\mathrm{med} 3 \& \mathrm{AN}=3045356$ 
425 Early Mobility Toolkit. (2014). Retrieved June 29, 2016,

426

427

428

429

430

431

432

433

434

435

436

437

438

439

440

441

442

443

444

445

446

447 from https://armstrongresearch.hopkinsmedicine.org/vap/vap/sessions.aspx

Ely, E. W., Margolin, R., Francis, J., May, L., Truman, B., Dittus, R., . . Inouye, S. K. (2001).

Evaluation of delirium in critically ill patients: Validation of the confusion assessment method for the intensive care unit (CAM-ICU).Critical Care Medicine, 29(7), 1370-1379.

Retrieved

from http://ovidsp.ovid.com.proxy.its.virginia.edu/ovidweb.cgi?T=JS\&CSC=Y\&NEWS=N

$\& \mathrm{PAGE}=$ fulltext $\& \mathrm{D}=$ med $4 \& \mathrm{AN}=11445689$

Foster, J., \& Kelly, M. (2013). A pilot study to test the feasibility of a nonpharmacologic intervention for the prevention of delirium in the medical intensive care unit. Clinical Nurse Specialist, 27(5), 231-238. doi:10.1097/NUR.0b013e3182a0b9f9

Fraser, D., Spiva, L., Forman, W., \& Hallen, C. (2015). Original research: Implementation of an early mobility program in an ICU. American Journal of Nursing, 115(12), 49-58. doi:10.1097/01.NAJ.0000475292.27985.fc

Hipp, D. M., \& Ely, E. W. (2012). Pharmacological and nonpharmacological management of delirium in critically ill patients. Neurotherapeutics, 9(1), 158-175. doi:http://dx.doi.org.proxy.its.virginia.edu/10.1007/s13311-011-0102-9

Inouye, S. K., Bogardus, S. T. J., Williams, C. S., Leo-Summers, L., \& Agostini, J. V. (2003). The role of adherence on the effectiveness of nonpharmacologic interventions: Evidence from the delirium prevention trial. Archives of Internal Medicine, 163(8), 958-964.

Retrieved

from http://ovidsp.ovid.com.proxy.its.virginia.edu/ovidweb.cgi?T=JS\&CSC=Y\&NEWS=N $\underline{\& P A G E=\text { fulltext } \& D=\text { med4\&AN=12719206 }}$ 
448 Needham, D. M., Korupolu, R., Zanni, J. M., Pradhan, P., Colantuoni, E., Palmer, J. B., .. . Fan,

449

450

451

452

453

454

455

456

457

458

459

460

461

462

463

464

465

466

467

468

469

470

471

472

473

474

475

476

477

478
E. (2010). Early physical medicine and rehabilitation for patients with acute respiratory failure: A quality improvement project.Archives of Physical Medicine and Rehabilitation, 91(4), 536-542. doi:10.1016/j.apmr.2010.01.002

Norman, G. R., \& Streiner, D. L. (2003). PDQ statistics. Hamilton, Ont.: B.C. Decker.

O'Mahony, R., Murthy, L., Akunne, A., Young, J., \& Guideline Development Group. (2011). Synopsis of the national institute for health and clinical excellence guideline for prevention of delirium. Annals of Internal Medicine, 154(11), 746-751. doi:10.7326/0003-4819-154-11$\underline{201106070-00006}$

Schweickert, W. D., Pohlman, M. C., Pohlman, A. S., Nigos, C., Pawlik, A. J., Esbrook, C. L., . . . Kress, J. P. (2009). Early physical and occupational therapy in mechanically ventilated, critically ill patients: A randomised controlled trial. Lancet, 373(9678), 1874-1882.

doi:10.1016/S0140-6736(09)60658-9 
479 Table 1.

480

481 Demographic Data

482

\section{Pre-Education Group $\quad$ Post-Education Group}

\begin{tabular}{rcc}
\hline Sex (\% female) & $70 \%$ & $46.7 \%$ \\
Age, years (mean, SD) & $60.9(18.8)$ & $56.1(20.7)$ \\
Race (\%) & & $80 \%$ \\
Caucasian & $16 \%$ & $13.3 \%$ \\
African American & $3.7 \%$ & $6.7 \%$ \\
Hispanic & $6,2-34,8$ \\
Hosu length of stay, days (median, range, IQR) & $2.7,1-37,5$ & $15.5,3-53,15$ \\
\hline
\end{tabular}

483

484

485

486

487

488

489

490

491

492

493

494

495

496

497

498

499

500

501

502

503

504

505 
506

507

508
Pre-Education

\section{Post-Education}

$\mathrm{n}=30$

$0 \%$

\section{Median \% delirium}

$14.6 \%$

positive days

509

Mann-Whitney U test; $p=0.139$

510

511

512

513

514 
515

516

517

\begin{tabular}{ccc}
\hline Sample Size & $\mathrm{n}=18$ & $\mathrm{n}=15$ \\
Mean \% Delirium Positive & $44.1 \%(35.2 \%)$ & $20.5 \%(28.3 \%)$ \\
Days (Standard Deviation) & & \\
\hline
\end{tabular}

518

Independent T-test; $p=0.045$ Pre-Education

Table 3.

Delirium outcomes excluding patients mobilized day of or day before ICU discharge

ost-Education
519

520

521

522

523

524

525

526

527

528

529

530

531

532

533

534

535

536

537

538

539

540

541

542

543

544

545

546

547

548

549

550

551 
Appendix A

Early Mobility Protocol

\begin{tabular}{|c|c|c|c|c|}
\hline START HERE & LEVEL 1 & LEVEL 2 & LEVEL 3 & LEVEL 4 \\
\hline \multirow{2}{*}{$\begin{array}{l}\text { Initial Activity Screening } \\
\text { Within 24-hrs of admission }\end{array}$} & $\begin{array}{c}\text { No / Low Cooperation } \\
\text { RASS - } 5 \text { to }-3\end{array}$ & $\begin{array}{c}\text { Moderate Cooperation } \\
\qquad \text { RASS }>-3 \text { to }-1\end{array}$ & $\begin{array}{c}\text { [Close to] Full cooperation } \\
\text { RASS }>-2 \text { to }-1\end{array}$ & $\begin{array}{l}\text { Full Cooperation } \\
\text { RASS }>0\end{array}$ \\
\hline & $\begin{array}{c}\text { FAILS } \\
\text { BASIC ASSESSMENT }\end{array}$ & $\begin{array}{c}\text { PASSES } \\
\text { BASIC ASSESSMENT }\end{array}$ & $\begin{array}{c}\text { PASSES } \\
\text { BASIC ASSESSMENT }\end{array}$ & $\begin{array}{c}\text { PASSES } \\
\text { BASIC ASSESSMENT }\end{array}$ \\
\hline \multicolumn{5}{|l|}{ BASIC ASSESSMENT } \\
\hline $\begin{array}{l}\text { Neurologic } \\
\text { RASS }>-3 \\
\text { Follows } 3-4 \text { commands } \\
\text { Respiratory } \\
\text { PEEP }<10 / \text { FIO2 }<70 \\
5 P O 2>90 \% \\
\text { RR }>5<40 \text { bpm }\end{array}$ & $\begin{array}{l}\text { BODY POSITIONING } \\
\text { - HOB }>30^{\circ} \\
\text { - Tuming Q } 2 \text { hours } \\
\text { - Splinting } \\
\text { - Consider specialty bed }\end{array}$ & $\begin{array}{l}\text { BODY POSIIONING } \\
\text { - HOB }>30^{\circ} \\
\text { - Tuming Q } 2 \text { hours } \\
\text { - Splinting } \\
\text { - Progressive upright } \\
\text { mobility } \\
\text { - Passive transfer to chair }\end{array}$ & $\begin{array}{l}\text { BODY POSIIIONING } \\
\text { - HOB }>30^{\circ} \\
\text { - Splinting } \\
\text { - Passive transfer to chair } \\
\text { - Sitting out of bed } \\
\text { - Standing with assistance }\end{array}$ & $\begin{array}{l}\text { BODY POSITIONING } \\
\text { - HOB }>30^{\circ} \\
\text { - Splinting } \\
\text { - Active transfer to chair } \\
\text { - Sirting out of bed } \\
\text { - Standing with min. or } \\
\text { no assist }\end{array}$ \\
\hline $\begin{array}{l}\text { Cardiovascular } \\
H R>50<140 \\
M A P>55<140 \\
S B P>90<200 \\
\text { No new or increasing } \\
\text { vasopressor infusion } \\
\text { No new arrhythmia }\end{array}$ & $\begin{array}{l}\quad \text { ACTIVITY } \\
\text { - Passive ROM } 2 \mathrm{x} d \\
\text { - Passive bed cycling } \\
\text { (Letto) }\end{array}$ & $\begin{array}{l}\text { ACTIVTTY } \\
\text { - Passive/active ROM } 2 \mathrm{x} \\
\text { d } \\
\text { - Resistance training (PT) } \\
\text { - Passive/active leg \&/or } \\
\text { arm cycling in bed } \\
\text { (Letto) or chair }\end{array}$ & $\begin{array}{l}\text { ACTIVITY } \\
\text { - Passive/active ROM } 2 \mathrm{x} \\
\text { d } \\
\text { - Resistance training (PT) } \\
\text { - Active leg \&/or arm } \\
\text { cycling in bed or chair } \\
\text { - Standing with assistance } \\
\text { - ADLs }\end{array}$ & $\begin{array}{l}\quad \text { ACTIVTTY } \\
\text { - Passive/active ROM } 2 \mathrm{x} \\
\text { d } \\
\text { - Resistance training (PT) } \\
\text { - Active leg \&/or arm } \\
\text { cycling in bed or chair } \\
\text { - Walking } \\
\text { - ADLs }\end{array}$ \\
\hline \begin{tabular}{c|c}
\multicolumn{1}{c|}{ BAIIS } & PASSES \\
start level 1 & Start level 2
\end{tabular} & $\begin{array}{c}\text { Tolerates level } 1 \\
\text { activities }\end{array}$ & $\begin{array}{c}\text { Tolerates level } 2 \\
\text { activities }\end{array}$ & $\begin{array}{c}\text { Tolerates level } 3 \\
\text { activities }\end{array}$ & $\begin{array}{l}\text { Ambulate progressively } \\
\text { longer distances }\end{array}$ \\
\hline
\end{tabular}


Appendix B

Early Mobility Worksheet

Date:

\section{Patient Label}

\begin{tabular}{|c|c|c|c|c|c|}
\hline \multicolumn{2}{|c|}{ START HERE } & LEVEL 1 & LBVBL 2 & LEYEL 3 & LBVI, 4 \\
\hline \multirow{2}{*}{\multicolumn{2}{|c|}{$\begin{array}{l}\text { Initial Activity Screening } \\
\text { Within 24-hrs of admission }\end{array}$}} & $\begin{array}{c}\text { No / Low Cooperation } \\
\text { RASS } 5 \text { to }-3\end{array}$ & $\begin{array}{c}\text { Moderate Cooperation } \\
\text { RASS }>-3 \text { to }-1\end{array}$ & $\begin{array}{c}\text { [Close to] Full cooperation } \\
\text { RASS }>-2 \text { to }-1\end{array}$ & $\begin{array}{c}\text { Full Cooperation } \\
\qquad R \wedge S S>0\end{array}$ \\
\hline & & $\begin{array}{c}\text { FAILS } \\
\text { BASIC ASSESSMENT }\end{array}$ & $\begin{array}{c}\text { PASSES } \\
\text { BASIC ASSESSMENT }\end{array}$ & $\begin{array}{c}\text { PASSES } \\
\text { BASICASSESSMENT }\end{array}$ & $\begin{array}{c}\text { PASSES } \\
\text { BASIC ASSFSSMENT }\end{array}$ \\
\hline \multicolumn{6}{|c|}{ BASIC ASSESSMENT } \\
\hline $\begin{array}{l}\text { Neurologic } \\
\text { RASS }>-3 \\
\text { Follows } 3- \\
\text { Respirater } \\
\text { PEEP }<10 \\
S P O 2>90 \text { : } \\
R R>5<4 C\end{array}$ & ommands & $\begin{array}{l}\text { BODY POSIIIONING } \\
\text { - HOB }>30^{\circ} \\
\text { - Tuming Q } 2 \text { hours } \\
\text { - Splinting } \\
\text { - Consider specialry bed }\end{array}$ & $\begin{array}{l}\text { BODY POSIIIONIVG } \\
\text { - HOB }>30^{\circ} \\
\text { - Tuming Q } 2 \text { bours } \\
\text { - Splinting } \\
\text { - Progressive uprigla } \\
\text { mobility } \\
\text { - Passive transfer to chair }\end{array}$ & $\begin{array}{l}\text { BODY POSIIIONIVG } \\
\text { - HOB }>30^{\circ} \\
\text { - Splinting } \\
\text { - Passive transfer to chair } \\
\text { - Sitting out of bed } \\
\text { - Standing with assistance }\end{array}$ & $\begin{array}{l}\text { BODY POSIIIONIVG } \\
\text { - HOB }>30^{\circ} \\
\text { - Splinting } \\
\text { - Active transfer to chair } \\
\text { - Sirting out of bed } \\
\text { - Standing with min or } \\
\text { no assist }\end{array}$ \\
\hline \multicolumn{2}{|c|}{$\begin{array}{l}\text { Cardiovascular } \\
\text { HR }>50<140 \\
M A P>55<140 \\
S 8 P>90<200 \\
\text { No new or increasing } \\
\text { vasopressor infusion } \\
\text { No new arrhythmia }\end{array}$} & $\begin{array}{l}\qquad \text { ACTIVTTY } \\
\text { - Passive ROM } 2 \mathrm{~s} \text { d } \\
\text { - Passive bed cycling } \\
\text { (Letto) }\end{array}$ & $\begin{array}{l}\text { ACTIVITY } \\
\text { - Passive/active ROM } 2 \mathrm{x} \\
\mathrm{d} \\
\text { - Resistance training (PT) } \\
\text { - Passive/active leg \&/or } \\
\text { arn cycling in bed } \\
\text { (Letto) or chair }\end{array}$ & $\begin{array}{l}\text { ACTIVTTY } \\
\text { - Passive active ROM } 2 \mathrm{x} \\
\text { d } \\
\text { - Resistance training (PT) } \\
\text { - Active leg \& or arm } \\
\text { cycling in bed or chair } \\
\text { - Standing with assistance } \\
\text { - ADLs }\end{array}$ & $\begin{array}{l}\text { ACTIVITY } \\
\text { - Passive active ROM } 2 x \\
\text { d } \\
\text { - Resistance training (PT) } \\
\text { - Active leg \& er arm } \\
\text { cycling in bed or chair } \\
\text { - Walking } \\
\text { - ADLs }\end{array}$ \\
\hline $\begin{array}{l}\text { FAIS: } \\
\text { Start level } 1\end{array}$ & $\begin{array}{l}\text { PASSES } \\
\text { Start level } 2\end{array}$ & $\begin{array}{c}\text { Tolerates level } 1 \\
\text { activities }\end{array}$ & $\begin{array}{c}\text { Tolerates level } 2 \\
\text { activities }\end{array}$ & $\begin{array}{c}\text { Tolerates level } 3 \\
\text { activities }\end{array}$ & $\begin{array}{l}\text { Ambulate progressively } \\
\text { longer distances }\end{array}$ \\
\hline \multicolumn{2}{|c|}{$\begin{array}{c}\text { PM.RB } \\
\text { CONSULTATIONS }\end{array}$} & OT: PROM / Splinting & $\begin{array}{l}\text { PT: If deconditioned } \\
\text { OT: PROM / splinting }\end{array}$ & $\begin{array}{l}\text { PT: If deconditioned } \\
\text { OT: ADL's / PROM } \\
\text { SLP: Cognitive }\end{array}$ & $\begin{array}{l}\text { PT: If deconditioned } \\
\text { OT: ADL's / PROM } \\
\text { SLP: co gnitive }\end{array}$ \\
\hline
\end{tabular}

Was the patient mobilized?

If so, to what level?

If the patient was not mobilized, why? (circle one)

Pt. failed basic assessment $\quad \mathrm{Pt} /$ family refused $\quad$ Time $\quad$ Staffing Lack of equipment

Safety Other (comment) 